\title{
Heterogeneous Populations of Outer Membrane Vesicles Released from Helicobacter pylori SS1 with Distinct Biological Properties
}

Abeer Ahmed Qaed Ahmed, ${ }^{1}$ Ruizhu Zheng, ${ }^{1}$ Ahmed M. E. Abdalla, ${ }^{3,}{ }^{*}$ Bianza Moise Bakadia, ${ }^{1}$ Fuyu Qi, ${ }^{1}$ Lin Xiao, ${ }^{2, *}$ Omar Mohammad Atta, ${ }^{1}$ Lin $\mathrm{Mao}^{1}$ and Guang Yang ${ }^{1, *}$

\begin{abstract}
Gram-negative bacteria release outer membrane vesicles (OMVs) with great potential in a variety of biomedical applications. The study aimed to investigate nutritional growth supplements (Horse Blood Serum (HBS), Fetal Bovine Serum (FBS), $\beta$ Cyclodextrin (CD), and Cholesterol (Chlos)) and their impact on Helicobacter pylori's (H. pylori's) OMVs biological properties, which the obtained OMVs were named ExHp-HBS, ExHp-FBS, ExHp-CD and ExHp-Chlose according to the growth supplement used. Sodium dodecyl sulphate-polyacrylamide gel electrophoresis (SDS-PAGE) showed a difference in protein components profile between all OMVs populations. Nuclear morphology for cells treated with $40 \mu \mathrm{g} / \mathrm{mL}$ of ExHp-CD displayed no change in nuclear morphology, while cells treated with ExHp-HBS, ExHp-FBS, and ExHp-Chlos showed chromatin condensation and nuclear fragmentation. Cell Counting Kit (CCK-8), lactate dehydrogenase (LDH), water-soluble tetrazolium salt (WST-1) assays showed no adverse effect for ExHp-CD in all used concentrations, while treated cells were negatively affected under higher concentrations for ExHp-HBS and ExHp-FBS $(40$ and $50 \mu \mathrm{g} / \mathrm{mL})$ or in almost all the used concentrations of ExHp-Chlos. Obtained OMVs populations were phagocyted by macrophage RAW 264.7 cells leading to activate macrophages and produce cytokines. Interleukin 10 (IL-10) and Interleukin 4 (IL-4) were significantly $(p<0.001)$ increased after stimulation with all obtained OMVs, while levels of Interferon gamma (IFN- $\gamma$ ) and Interleukin 12 (IL-12) were not significantly increased. All OMVs populations increased CD206 ratio over CD86 ratio, demonstrating $\mathrm{M}_{2}$-phenotype polarization. Current findings revealed that growth supplements influenced OMVs biological properties while inducing $\mathrm{Th}_{2}$-immune response. This knowledge could determine which type of OMVs population for the required biomedical application.
\end{abstract}

Keywords: Outer membrane vesicles, Helicobacter pylori SS1, Th2-immune response, Macrophage RAW 264.7 cells, OMVs populations.

Received: 12 April 2021; Accepted: 15 May 2021.

Article type: Research article.

\section{Introduction}

All organisms representing various life forms were found to

\footnotetext{
${ }^{1}$ Department of Biomedical Engineering, College of Life Science and Technology, Huazhong University of Science and Technology, 1037 Luoyu Road, Wuhan 430074, China.

2 School of Biomedical Engineering, Sun Yat-sen University, Guangzhou, 510006, China.

3 Department of Biochemistry, College of Applied Science, University of Bahri, Khartoum, 1660/11111, Sudan.

*E-mail: yang_sunny@yahoo.com (G. Yang),

xiaolin23@mail.sysu.edu.cn (L. Xiao),

ahmedbio1@hotmail.com (Ahmed M. E. Abdalla)
}

release different extracellular vesicles naturally as part of their growth and all other physiological processes ${ }^{[1,2]}$ Both Grampositive and Gram-negative bacteria release extracellular vesicles in a natural process necessary for interactions between inter-species and inter-kingdoms. ${ }^{[3]}$ Bacterial membrane vesicles are involved in cellular crosstalk and possess unique targeting and packaging abilities and many other essential functions. ${ }^{[4,5]}$ Recently, increased attention has recognized extracellular vesicles as a promising candidate for various biomedical applications such as immune modulation, drug delivery, cancer therapy, vaccine development, detoxification, phototherapy, and anti-bacterial agents. ${ }^{[6-14]}$ Outer membrane vesicles (OMVs) from Gram-negative 
bacteria hold great importance. They compose of various components (Fig. 1) such as lipids, proteins (e.g. enzymes and structural proteins), carbohydrates, and genetic materials (e.g. DNA and RNAs). ${ }^{[15]}$ Several factors were found to influence the production of OMVs, such as growth stage, infection settings, and biofilms. ${ }^{[4,16-19]}$ These findings highlighted the crucial roles that OMVs might play in different biological processes and the different roles each OMVs population should participate in. Thus, the change of OMVs composition might be expected depending on the part that they are required to play. Moreover, the environmental conditions and its contents around the bacterial cells could influence OMVs production, such as antibiotics presence and temperature changes. ${ }^{[4,18,20,21]}$ Thus, researchers should investigate further the variation of OMVs populations from a certain bacterial species and the different factors involved in this phenomenon. This could lead to finding the required OMVs population with the desired biological function. Thus, the specific required OMVs population could be used in the needed biomedical applications such as cancer immunotherapy, anti-bacteria adhesion agents, bacterial vaccine development, and drug delivery vehicles depending on the specific needed biological function. ${ }^{[22]}$ Moreover, OMVs components could be analyzed and investigated if the need is to find novel components (e.g. antigens, functional proteins, biomarkers, enzymes, etc.) to be used in further applications.

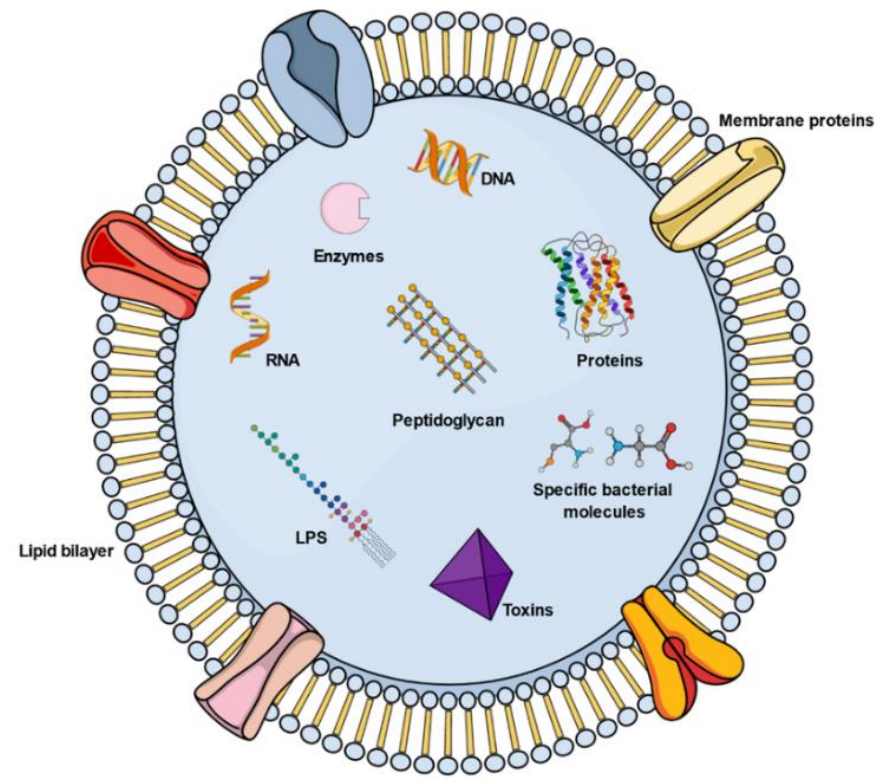

Fig. 1 A graphical overview of outer membrane vesicle from Gram-negative bacteria. OMVs are contained from a continuous lipid bilayer that is composed of a variety of cytoplasmic and membrane proteins, toxins, enzymes, nucleic acids, peptidoglycans, and biomolecules derived from their parental bacterial cell.

Helicobacter pylori (H. pylori), a gastric Gram-negative bacterium, is a widespread bacterium that infects half of the people worldwide, and in some countries, the infection rate reached $79 \%$ of the population. ${ }^{[23-25]}$ Approximately 4.4 billion of the global population are infected with $H$. pylori worldwide. ${ }^{[25]} H$. pylori infection and its associated diseases remain persistent and hard to treat. This could be attributed to H. pylori resistance against antibiotics such as levofloxacin, clarithromycin, and metronidazole reaching to alarming level globally, which have a significant impact on the efficacy of $H$. pylori treatment. ${ }^{[26]}$ Despite several treatment regimens that proposed (hybrid therapy, sequential therapy, concomitant therapy, probiotics supplemented triple therapy, etc.), the treatment choice is highly dependent on many factors such as the viability of susceptibility testing, local empiric therapy, the probiotic strain specificity, among many other factors. ${ }^{[23]}$ Therefore, it is essential to find other effective measures to overcome $H$. pylori infection and its associated diseases.

$H$. pylori have various components with distinct biological functions. For instance, H. pylori 's outer membrane proteins (OMPs) own several biological functions that include maintaining the structure of the outer membrane, materials transportation, and contributing with interacting with the host. ${ }^{[27]}$ OMPs expression in different strains is attributed to the H. pylori virulence. Moreover, OMPs pathogenicity could be achieved via the mechanisms of 1) adhesion, 2) bacterial cell-penetrating the defense barriers, and 3) immune system evasion. ${ }^{[28]}$ Although some H. pylori's components (e.g. vacuolating cytotoxin $\mathrm{A}(\mathrm{Vac} \mathrm{A}))$ were found to stimulate the immune response, however, their cytotoxic effect limits their use in vaccine development. ${ }^{[29,30]}$ Furthermore, they could alter host cells' functions in unfavorable ways and negatively impact their normal functions. Moreover, $H$. pylori observed to cause apoptosis in macrophages as well as epithelial cells through virulence factors/proapoptotic factors that include Lipopolysaccharides (LPS), VacA, Cytotoxin-associated gene A (CagA), Urease (Ure), $\gamma$-glutamyl transpeptidase and Fas ligand (FasL). ${ }^{[1-36]}$ Besides, several outer membrane proteins of $H$. pylori were found to affect cell processes variously. For instance, LPS was observed to inhibit cell proliferation; meanwhile, glycine acid extract (GE), CagA, and UreA elevate cell proliferation. ${ }^{[37,38]}$ Moreover, VacA was found to have a direct influence against $\mathrm{T}$ cells, epithelial cells, and phagocytes via inhibiting cell proliferation. ${ }^{[39-43]}$

Thus, the current work aimed to investigate the influence of the medium growth supplements on the variation of OMVs released from $H$. pylori. This could help in finding the specific OMVs population with the desired biological function for the required application.

\section{Materials and methods 2.1 Cell culture}

Macrophage RAW 264.7 cell line (RAW 264.7) (Procell life science \& technology Co., Ltd., Wuhan, China) were used and primarily maintained in Dulbecco's Modified Eagle Medium (DMEM) containing 10\% FBS (Gibco/Invitrogen, Carlsbad, $\mathrm{CA})$ at $37{ }^{\circ} \mathrm{C}, 5 \% \mathrm{CO}_{2}$ and humid atmosphere. For several assays, serum-free-DMEM was used to avoid false results due to exosomes and proteins present in FBS. 


\subsection{Helicobacter pylori strain and growth conditions}

Mouse-adapted Helicobacter pylori SS1 was thankfully provided by Prof. Longrui Pan, Department of Pharmacology, Hubei University of Medicine, Shiyan, China. Columbia blood agar supplemented with $10 \%$ defibrinated -whole blood from sheep, $10 \mu \mathrm{g} / \mathrm{mL}$ vancomycin, $2.5 \mu \mathrm{g} / \mathrm{mL}$ amphotericin $\mathrm{B}, 5 \mu \mathrm{g} / \mathrm{mL}$ trimethoprim, and $2.5 \mathrm{IU} / \mathrm{mL}$ polymyxin B. Plates inoculated with $H$. pylori were incubated for $72 \mathrm{~h}$ in a humidified atmosphere at $37{ }^{\circ} \mathrm{C}$ and $5 \%$ of $\mathrm{CO}_{2}$. Brain Heart Infusion broth (BHI) supplemented with $10 \%$ FBS (Gibco/Invitrogen, Carlsbad, CA) and $10 \mu \mathrm{g} / \mathrm{mL}$ vancomycin were used for maintaining $H$. pylori, such as quantifying bacterial numbers and freezer stock preparations. However, for OMVs isolation, BHI broth supplemented with different nutritional supplements ( $\beta$-Cyclodextrin, Cholesterol, and exosomes depleted Fetal Bovine Serum (FBS) and Horse Blood Serum (HBS)) and $10 \mu \mathrm{g} / \mathrm{mL}$ vancomycin were used.

\subsection{OMVs isolation}

Brain Heart Infusion broth $(198 \mathrm{~mL}$ in $250 \mathrm{~mL}$ flask) was supplemented with $10 \mu \mathrm{g} / \mathrm{mL}$ vancomycin, and then different growth supplements were used separately, which were $\beta$ Cyclodextrin (1 g/L), 10\% FBS, 10\% HBS or Cholesterol (50 $\mathrm{mg} / \mathrm{L}$ ). Each supplemented BHI media was inoculated with 2 $\mathrm{mL}$ of $H$. pylori inoculum concentration of $1.5 \times 10^{8} \mathrm{CFU} / \mathrm{mL}$ (compared to a $0.5 \mathrm{McF}$ arland turbidity standard) until the final concentration of $1.5 \times 10^{4} \mathrm{CFU} / \mathrm{mL}$. The inoculated culture was incubated for $72 \mathrm{~h}$ until the $\mathrm{OD}_{600}$ value of the cultured medium reached approximately 1.0 , which indicates reaching the logarithmic growth phase. Approximately 200 $\mathrm{mL}$ of $H$. pylori culture in BHI broth was collected for OMVs isolation using ExoBacteria ${ }^{\mathrm{TM}} \mathrm{OMV}$ Isolation Kit (System Biosciences (SBI), Palo Alto, CA). Briefly, when desired OD is reached, bacterial culture was centrifuged at $5000 \mathrm{rpm}$ for $20 \mathrm{~min}$ at $4{ }^{\circ} \mathrm{C}$. To eliminate any cellular debris, the supernatant was transferred to a new tube and centrifuged again at $5000 \mathrm{rpm}$ for $20 \mathrm{~min}$ at $4{ }^{\circ} \mathrm{C}$. The supernatant was collected and filtered through a $0.45 \mu \mathrm{m}$ filter. Then, the supernatant was filtered again using a $0.22 \mu \mathrm{m}$ filter. OMV Binding Resin was mixed by shaking, and $1 \mathrm{~mL}$ of the OMV Binding Resin was added into the column. The column was equilibrated by adding the $1 \times$ Binding Buffer $(10 \mathrm{~mL})$, and the solution was allowed to completely flow through and further discarded. Clarified bacterial culture supernatant was added $(30 \mathrm{~mL})$ to the resin, and the column was capped and incubated on a rotating rack $(30 \mathrm{~min})$ to allow OMVs binding. The resin/supernatant mixture was allowed to flow through by uncapping the bottom and top of the column. The resin was washed with $15 \mathrm{~mL}$ Binding Buffer, and the flow-through was discarded. This washing step was repeated twice. After capping the bottom of the column, $1.5 \mathrm{~mL}$ OMV Elution Buffer was added, incubated for $2 \mathrm{~min}$ at room temperature with gentle shaking every $30 \mathrm{~s}$. the column was uncapped at the bottom, and the eluate that contains the OMVs were collected in new microcentrifuge tubes. OMVs were washed using Amicon Ultra centrifugal Filter Device 3K MWCO. Protease inhibitor cocktail was added, and OMVs solution was aliquoted in microcentrifuge tubes $(50 \mu \mathrm{L})$ and stored at $-80^{\circ} \mathrm{C}$ until further use.

The protein concentration of OMVs was determined using BCA Protein Assay (Beyotime, Jiangsu, China). This was considered as the concentration of the obtained OMVs. The obtained OMVs were named ExHp-HBS, ExHp-FBS, ExHp$\mathrm{CD}$, and ExHp-Chlos according to the growth supplement used.

\subsection{Transmission electron microscopy (TEM)}

Obtained OMVs were suspended in phosphate-buffered saline (PBS) in a concentration of $0.1 \mathrm{mg} / \mathrm{mL}$. An amount of $10 \mu \mathrm{L}$ of OMVs suspension solution was loaded on the grids of formvar carbon-coated 300 mesh for $30 \mathrm{~min}$ at $25{ }^{\circ} \mathrm{C}$. The excess fluid was removed using filter paper by contacting filter paper lightly with the grid edge. The grids were partially covered using a Petri dish and left to dry overnight under room temperature. Finally, the air-dried grids containing OMVs were observed by TEM (HITACHI Transmission Electron Microscope, HT7700, Japan).

\subsection{Dynamic light scattering (DLS)}

OMVs were diluted with PBS to reach the concentration of 0.1 $\mathrm{mg} / \mathrm{mL}$. The size measurements were conducted using Zetasizer Nano Series (Malvern Instruments, Herrenberg, Germany).

\subsection{Sodium dodecyl sulfate polyacrylamide gel electrophoresis (SDS-PAGE)}

Protein contents of different OMVs populations were analyzed using $12 \%$ SDS-PAGE. First, $20 \mu \mathrm{g}$ of each OMVs population were boiled in SDS loading buffer (Beyotime, Jiangsu, China) for $5 \mathrm{~min}$, and then were separated by 12\% SDS-PAGE and followed by staining with Coomassie blue staining solution.

\subsection{Macrophage RAW 264.7 viability assay}

The viability assay was done using Cell Counting Kit (CCK8), Dojindo Laboratories, Kumamoto, Japan. Briefly, different concentrations of each OMVs population was prepared using sterile PBS as $5 \mu \mathrm{g} / \mathrm{mL}, 10 \mu \mathrm{g} / \mathrm{mL}, 20 \mu \mathrm{g} / \mathrm{mL}, 30 \mu \mathrm{g} / \mathrm{mL}, 40$ $\mu \mathrm{g} / \mathrm{mL}$ and $50 \mu \mathrm{g} / \mathrm{mL}$, respectively. The macrophage RAW264.7 cells were seeded in 96-well plates with a density of $3.5 \times 10^{5}$ cells/well and then were incubated at $37^{\circ} \mathrm{C}$ under $5 \% \mathrm{CO}_{2}$ and humid atmosphere. After $24 \mathrm{~h}$ of incubation, cells were stimulated by replacing culture medium with fresh medium $(100 \mu \mathrm{L})$ containing different concentrations of each OMVs population (previously mentioned) or PBS alone as controls (positive and negative). All the 96-well plates were incubated under the same previous conditions for $24 \mathrm{~h}$. After the incubation period, the medium was replaced by $100 \mu \mathrm{L}$ of fresh medium plus $10 \mu \mathrm{L}$ of CCK-8 reagent, and plates were incubated for further $2 \mathrm{~h}$. Finally, at $450 \mathrm{~nm}$, the absorbance was measured using a microplate reader (Multiskan EX, 
Thermo Fisher Scientific, USA). Cell viability of macrophage RAW 264.7 was calculated as the absorbance ratio of the stimulated cells to that of cells of the control groups as the following equation $(\mathrm{I})^{*}$ :

$\mathrm{I}=\%$ Cells viability $=$ (absorbance sample - absorbance blank $) /\left(\right.$ absorbance $_{\text {control }}-$ absorbance $\left._{\text {blank }}\right) \times 100$

\subsection{Nuclear change of macrophage RAW 264.7 cells}

Macrophage RAW264.7 cells were cultured at a density of $2.56 \times 10^{5}$ cells $/ \mathrm{mL}$ in glass coverslips using a complete medium and were incubated for $4 \mathrm{~h}$ to allow cell attachment. After cell attachment, the medium was replaced with prewarmed DMEM containing different OMVs populations (40 $\mu \mathrm{g} / \mathrm{mL}$ ). Cells incubated with DMEM medium only were used as controls. Afterward, coverslips were incubated at $37^{\circ} \mathrm{C}, 5 \%$ $\mathrm{CO}_{2}$, and humid atmosphere for $24 \mathrm{~h}$. After incubation, media was discarded from the coverslips, and cells were washed using pre-warmed PBS three times. Cells were fixed with $4 \%$ paraformaldehyde $(\mathrm{PFA}, \mathrm{v} / \mathrm{v})$ for $10 \mathrm{~min}$ at room temperature. Three washing steps were followed using PBS for 10 min each time. Using $200 \mu \mathrm{L}$ of DAPI solution $(100 \mathrm{nM})$, cell nuclei were stained by covering the coverslips for $5 \mathrm{~min}$. Cold PBS was used to wash coverslips three times. Fluorescence observation under confocal microscopy was conducted for nuclear segmentation and condensation, which was examined at $40 \times$ magnification using Olympus Ultra-Sensitive Confocal Microscope System, FV3000, Japan. One hundred cells were examined for each sample.

\subsection{Hemolysis assay}

One $\mathrm{mL}$ of fresh sheep blood (Hopebio, Qingdao, China) was washed three times by $2 \mathrm{~mL}$ of PBS solution. Then, the red blood cells (RBCs) pellet was dispersed in $20 \mathrm{~mL}$ of PBS solution. ExHp-HBS, ExHp-FBS, ExHp-CD, and ExHpChlos were prepared using PBS $(10 \mu \mathrm{g} / \mathrm{mL})$. Triton $\times-100$ and PBS were used as positive and negative controls, respectively. An amount of $60 \mu \mathrm{L}$ of each OMVs population, Triton $\times-100$ or PBS, were added to $1140 \mu \mathrm{L}$ of previously prepared RBC solution in Eppendorf tubes. Then, tubes were incubated at $37{ }^{\circ} \mathrm{C}$ and $100 \mathrm{rpm}$ for $4 \mathrm{~h}$. After incubation, the suspensions were centrifuged at $10000 \mathrm{rpm}$ for $6 \mathrm{~min}$. First, results were observed visually, then $200 \mu \mathrm{L}$ of each supernatant was added to a 96-well plate. The absorbance was read at $550 \mathrm{~nm}$ using a microplate reader (MultiskanEX, Thermo Fisher Scientific, USA). The percent (\%) of hemolysis was determined as the following (II):

II $=$ Hemolysis $(\%)=$ (absorbance sample - absorbance PBS $) /($ absorbance $\operatorname{Triton} \times-100-$ absorbance $\mathrm{PBS}) \times 100$.

\subsection{LDH release assay}

To test the cytotoxic effect of each OMVs population, lactate dehydrogenase (LDH) assay was performed according to the manufacturer's recommendations (Beyotime, Jiangsu, China). Macrophage RAW264.7 cells were seeded in 96-well plates with a density of $2.42 \times 10^{5}$ cells/well. After $24 \mathrm{~h}$ of incubation,
$5,10,20,30,40$, and $50 \mu \mathrm{g} / \mathrm{mL}$ of each OMVs population were added separately in each well set and were incubated for a further 48 h. RAW264.7 cells incubated with DMEM medium and DMEM medium alone without cells were used as positive and negative controls, respectively. An amount of 120 $\mu \mathrm{L}$ of culture supernatant from each well in each well set that belongs to each tested group was transferred into a new 96well plate in corresponding wells. LDH released into the medium was tested by mixing the transferred culture medium with the reaction mixture $(60 \mu \mathrm{L})$. At room temperature, the mixture was incubated in the dark for $30 \mathrm{~min}$ warped in aluminum foil, and placed on a horizontal shaker in low-speed shaking. Then, the absorbance was measured at $490 \mathrm{~nm}$, and the LDH release was calculated.

\subsection{WST-1 cell proliferation assay}

The effect of different OMVs populations on metabolic activities and cell proliferation was monitored using the watersoluble tetrazolium salt (WST-1) assay of the mitochondrial dehydrogenase as instructed by the manufacturer (Beyotime, Jiangsu, China). Macrophage RAW264.7 cells were seeded in 96-well plates with a density of $3.2 \times 10^{5}$ cells/well. After 24 $\mathrm{h}$ of incubation, the medium was replaced with a DMEM medium containing $5 \mu \mathrm{g} / \mathrm{mL}$, and $10 \mu \mathrm{g} / \mathrm{mL}$ of each OMVs population were added separately in each well set and further incubated for 24 and $48 \mathrm{~h}$. RAW264.7 cells incubated without any agent and DMEM medium without cells were served as positive and negative controls, respectively. For each concentration, the experiment was repeated five times under the same conditions. After each incubation time, $10 \mu \mathrm{L}$ of WST-1 solution (to $100 \mu \mathrm{L}$ of culture volume) was added to each well. The 96-well plates were incubated further for $2 \mathrm{~h}$ in the dark at $37{ }^{\circ} \mathrm{C}$ and $5 \% \mathrm{CO}_{2}$. Then, the 96 -well plates were placed on a shaker for $1 \mathrm{~min}$ to mix the system. A microplate (ELISA) reader was then used to measure the absorbance at $450 \mathrm{~nm}$ for samples and at $650 \mathrm{~nm}$ for reference, and the percentage of cell proliferation was calculated.

\subsection{OMVs uptake by macrophage RAW 264.7 cells}

OMVs labeling was done by using fluorescent dye 3,3' dioctadecyloxacarbocyanine perchlorate (DiO, Beyotime, Jiangsu, China). Briefly, OMVs solution was prepared by suspending OMVs into sterile PBS to prepare the final concentration of $100 \mu \mathrm{g} / \mathrm{mL}$. One $\mathrm{mL}$ of each OMVs population solution was incubated with $6 \mu \mathrm{L}$ of $\mathrm{DiO}$ stock solution $(10 \mu \mathrm{M})$ in the dark at $37{ }^{\circ} \mathrm{C}$ for $1 \mathrm{~h}$ with gentle agitation. The extra unbound dye was removed by using Nanosep centrifugal device MWCO of $3 \mathrm{~K}$ (Pall life sciences, Ann Arbor, MI 48103-9019 USA), and labeled OMVs were washed three times using sterile PBS. DiO-labeled OMVs were resuspended using DMEM. Aliquots of labeled OMVs were stored at $-80^{\circ} \mathrm{C}$ until further use.

RAW264.7 cells were cultured in glass coverslips at $4.3 \times$ $10^{5}$ cells $/ \mathrm{mL}$ with complete medium and incubated at $37^{\circ} \mathrm{C}$, $5 \% \mathrm{CO}_{2}$, and humid atmosphere for $4 \mathrm{~h}$ to allow cell 


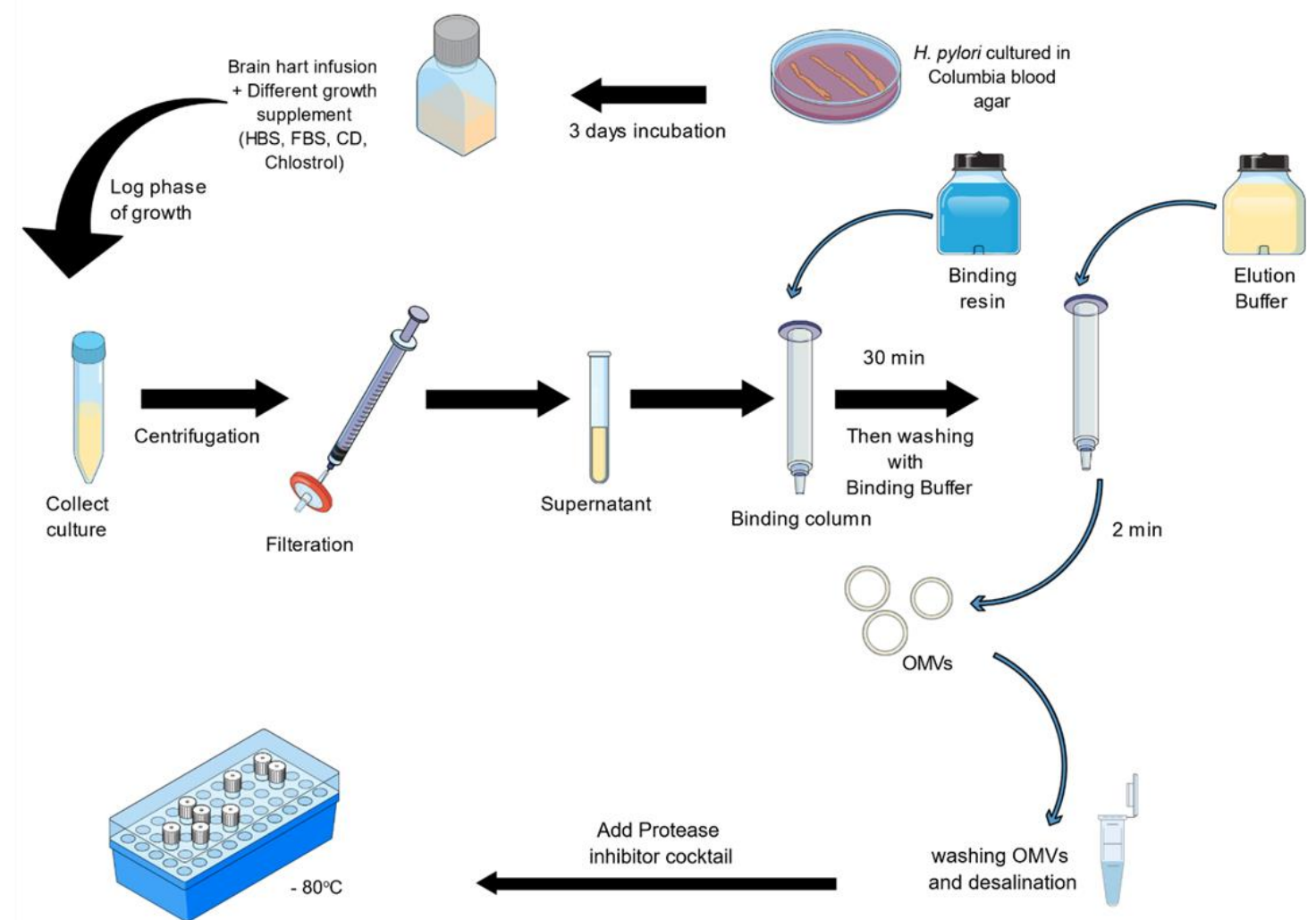

Fig. 2 Schematic illustration of OMVs isolation and preparation.

attachment. Then, the medium was replaced with pre-warmed DMEM containing $10 \mu \mathrm{g} / \mathrm{mL}$ of each DiO-labeled OMVs population, and then each glass coverslip was incubated further $24 \mathrm{~h}$ to allow OMVs uptake. Cells without the addition of DiO-labeled OMVs were used as controls. After incubation, cells were washed three times with PBS. Then, using $4 \%$ paraformaldehyde (PFA, v/v) the cells were fixed for $20 \mathrm{~min}$ followed by three times washing steps using PBS. To stain cell nuclei, 2-(4-Amidinophenyl)-6-indolecarbamidin dihydrochloride (DAPI, Beyotime, Jiangsu, China) was used. DAPI staining solution was added to cover the sample and left at room temperature for $3 \sim 5 \mathrm{~min}$. DAPI staining solution was removed and washed three times with cold PBS. Finally, the cells were viewed using a confocal laser scanning microscope (Olympus Ultra-Sensitive Confocal Microscope System, FV3000, Japan).

\subsection{Cytokines assay of macrophage RAW 264.7 cells}

The macrophage RAW264.7 cells were seeded in 24-well plates with a density of $4.5 \times 10^{5}$ cells/well, and then were incubated for $24 \mathrm{~h}$ at $37{ }^{\circ} \mathrm{C}$ under $5 \% \mathrm{CO}_{2}$ and humid atmosphere. Then, the medium was replaced with a fresh serum-free DMEM medium that contains $10 \mu \mathrm{g} / \mathrm{mL}$ of each OMVs population. A fresh serum-free DMEM medium was used to avoid any cytokines production due to exosomes and proteins present in the Fetal Bovine Serum. A serum-free DMEM medium was added to control wells. After $24 \mathrm{~h}$ incubation, the cell-free supernatants from all groups were collected and analyzed for IFN-gamma (IFN- $\gamma$ ), interleukin-
12 (IL-12), interleukin-4 (IL-4), and interleukin-10 (IL-10). The assays were determined by specific colorimetric sandwich ELISA assay kits according to the manufacturer's directions (Proteintech, Rosemont, IL 60018, USA).

\subsection{Differentiation of macrophage RAW 264.7 cells}

Immunofluorescence staining assay for stimulated macrophage RAW 264.7 cells was applied to evaluate macrophage polarization. Cells were seeded on glass coverslips at a density of $2.5 \times 10^{5}$ cells $/ \mathrm{mL}$, and then they were incubated at $37{ }^{\circ} \mathrm{C}, 5 \% \mathrm{CO}_{2}$, and humid atmosphere for $4 \mathrm{~h}$. Following cell attachment, the cells were stimulated with $10 \mu \mathrm{g} / \mathrm{mL}$ of each OMVs population prepared in serum-free DMEM medium and further incubated under the same conditions for $24 \mathrm{~h}$. Macrophage RAW 264.7 cells incubated only with serum-free DMEM medium were used as controls. The culture medium was discarded, and cells were washed with pre-warmed PBS three times. Cells were fixed with $4 \%$ PFA for $20 \mathrm{~min}$ at $4{ }^{\circ} \mathrm{C}$. After fixation, cells were punched with $0.2 \%$ Triton $\times-100$-PBS for $5 \mathrm{~min}$. Then, cells were blocked with 3\% Bovine Serum Albumin (BSA)-PBS for $1 \mathrm{~h}$ at room temperature. Then, RAW 264.7 cells were incubated with $50 \mu \mathrm{L}$ of the specific primary antibodies on the coverslips for $1 \mathrm{~h}$ at room temperature in a moist container. The primary antibodies against the M1 marker CD86 (1:100, CD86 polyclonal antibody, Proteintech, Rosemont, IL 60018, USA) and the M2 marker CD206 (1:100, CD206 polyclonal antibody, Proteintech, Rosemont, IL 60018, USA) were used. After $1 \mathrm{~h}$ incubation, coverslips were washed three times using 
(a)
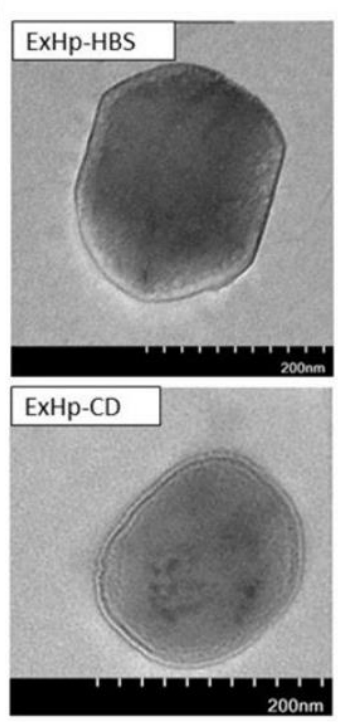
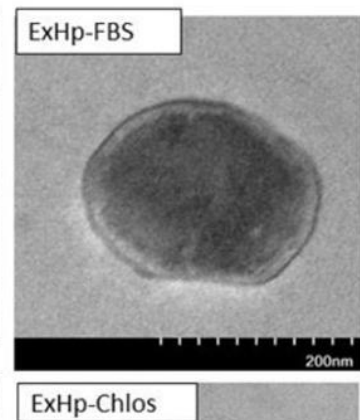

\section{ExHp-Chlos}

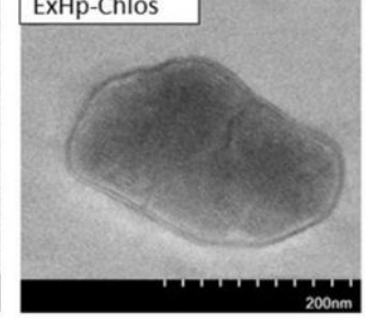

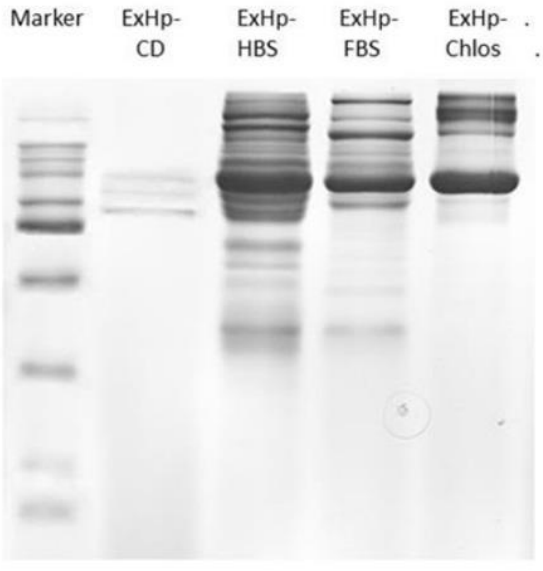

(c)

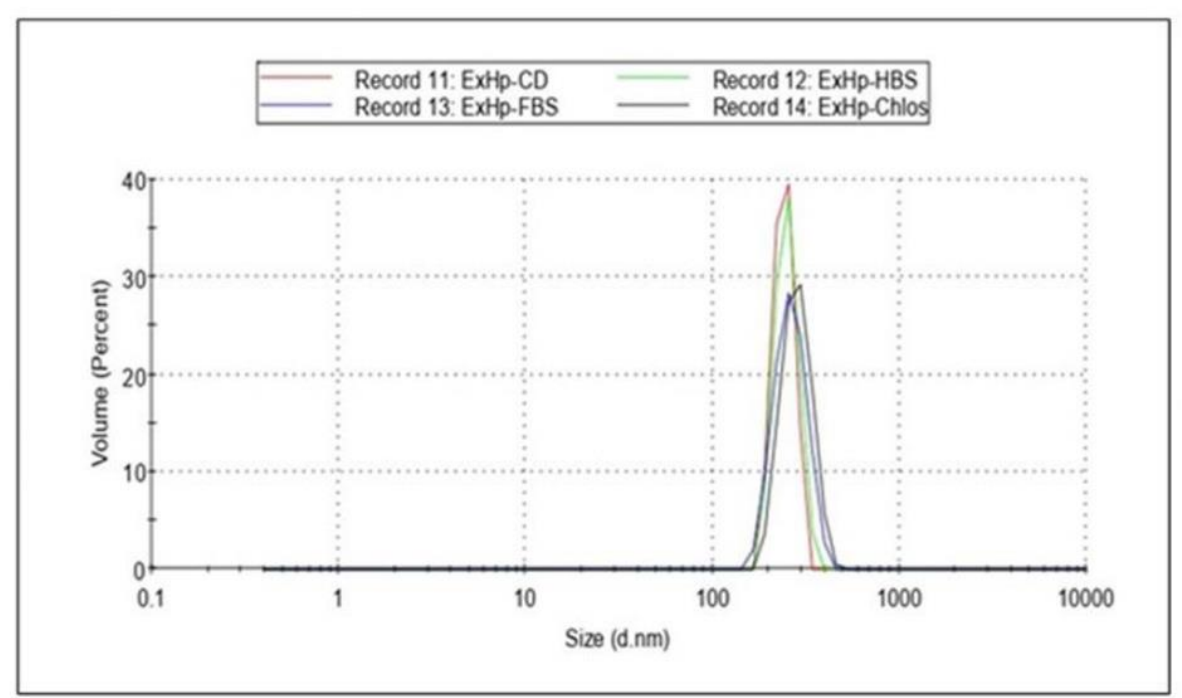

Fig. 3 Characterization of the different populations of OMVs. (a) TEM micrograph of the isolated OMVs revealed the spherical shape of OMVs with intact continuous bilayer membrane, Scale bar $=200 \mathrm{~nm}$. (b) ExHp-HBS, ExHp-FBS, ExHp-CD, and ExHpChlos proteins profile separated by SDS-PAGE 12\% gel and stained with Coomassie blue (c) DLS analysis of the isolated OMVs.

PBS, followed by adding CoraLite488-conjugated Affinipure Goat Anti-Rabbit IgG $(\mathrm{H}+\mathrm{L})(50 \mu \mathrm{L}, 1: 100$, Proteintech, Rosemont, IL 60018, USA) on each coverslip and incubation at room temperature in a dark-moist container for $1 \mathrm{~h}$. Then, three times washing steps were done using PBS for 5 min each, followed by nucleus staining with DAPI $(100 \mathrm{nM})$ for $5 \mathrm{~min}$. Cold PBS was used to wash coverslips three times, and then coverslips were mounted in $15 \%$ glycerol. Fluorescence observation under confocal microscopy was conducted, and five different fields were randomly selected from each sample, and then DAPI, CD86, and CD206 were observed and analyzed.

\subsection{Statistical analysis}

Data were analyzed and presented using OriginPro 2018 software (Origin Lab, Northampton, MA 01060, USA). All data obtained were expressed as the mean \pm standard deviation
(SD) of at least five experiments. P-values of 0.05 or less carried out using a $t$-test were considered statistically significant.

\section{Results and discussion}

3.1 Identification and characterization of OMVs populations derived from $\boldsymbol{H}$. pylori

Despite the importance of OMVs released as part of the normal growth of Gram-negative bacteria, the effect of the nutritional contents in the cultured medium on the OMVs production is not explored. In the current study, the impact of growth supplements on OMVs released from $H$. pylori SS was examined. All obtained OMVs were isolated, washed, and then stored for further evaluation (Fig. 2). Four OMVs populations were obtained from H. pylori SS in BHI medium supplemented with Horse Blood Serum (ExHp-HBS), FBS (ExHp-FBS), $\beta$-Cyclodextrin (ExHp-CD), or Cholesterol 
(ExHp-Chlos). DLS analysis (Fig. 3c) showed the size of OMVs populations peaked at a mean diameter of $250 \mathrm{~nm}$. TEM results showed that all obtained OMVs populations were observed to have intact continuous bilayer membrane and were spherical in shape Fig. 3a. There was no bacterial debris present in the micrograph, confirming the purity of the isolated OMVs (Fig. 3a). These results are confirming the findings of previous reports stating that OMVs derived from Gramnegative bacteria to be spherical bilayer membrane vesicles ranging from 20 to $500 \mathrm{~nm} \cdot{ }^{[44-48]}$

To explore the difference between the obtained OMVs populations, SDS-PAGE analysis was performed using $12 \%$ SDS-PAGE. Results showed a difference in protein components between all OMVs populations (Fig. 3b). The data revealed that all four OMVs populations contained various protein bands that appeared between 150 and $25 \mathrm{kDa}$.

\subsection{Evaluation of RAW 264.7 viability towards OMVs populations}

To determine the compatibility of OMVs populations, the effect of OMVs on the viability of macrophage RAW 264.7 cells were evaluated using CCK-8. As indicated in Fig. 4a, the ExHp-CD didn't affect the viability of the macrophage RAW 264.7 cells in all the tested concentrations $(5-50 \mu \mathrm{g} / \mathrm{mL})$ and the viability of cells was significantly increased compared to the control groups $(5 \mu \mathrm{g} / \mathrm{mL}=118.7 \pm 8 \%, 10 \mu \mathrm{g} / \mathrm{mL}=125.7$ $\pm 3.6 \%, 20 \mu \mathrm{g} / \mathrm{mL}=132.3 \pm 7.7 \%, 30 \mu \mathrm{g} / \mathrm{mL}=133 \pm 10.05 \%$, $40 \mu \mathrm{g} / \mathrm{mL}=128.4 \pm 2.7 \%$ and $50 \mu \mathrm{g} / \mathrm{mL}=126.8 \pm 5.07 \%$ ). However, for ExHp-Chlos, results showed that the viability of cells was significantly reduced from concentrations $\geq 10$ $\mu \mathrm{g} / \mathrm{mL}(5 \mu \mathrm{g} / \mathrm{mL}=100.2 \pm 4.2 \%, 10 \mu \mathrm{g} / \mathrm{mL}=94.5 \pm 4.8 \%, 20$ $\mu \mathrm{g} / \mathrm{mL}=69.7 \pm 6.1 \%, 30 \mu \mathrm{g} / \mathrm{mL}=60.4 \pm 4.9 \%, 40 \mu \mathrm{g} / \mathrm{mL}=$ $58.3 \pm 3.2 \%$ and $50 \mu \mathrm{g} / \mathrm{mL}=56.9 \pm 3.26 \%$ ) compared to untreated cells $(p<0.05)$ suggesting major toxic effect on cell viability in these concentrations. Meanwhile for ExHp-HBS and ExHp-FBS, cell viability was decreased only in the higher concentrations $(40 \mu \mathrm{g} / \mathrm{mL}$ and $50 \mu \mathrm{g} / \mathrm{mL})$ compared to lower concentrations ( 5 to $30 \mu \mathrm{g} / \mathrm{mL}$ ). This was confirmed via other experiments which were done in this study and was discussed in the discussion section.

Various biomedical applications require the used agent to be biocompatible and safe for clinical use. Although some bacterial virulence factors were used in biomedical applications, such as regulating immune response, several limitations have been raised against their cytotoxic effect, which hinders their use in clinical applications. ${ }^{[29]}$ Thus, the biocompatibility of ExHp-HBS, ExHp-FBS, ExHp-CD, and ExHp-Chlos were evaluated. Cell viability was measured by testing the impact of the obtained OMVs populations on macrophage RAW 264.7 cells. Among all OMVs populations, ExHp-CD was found to be the most biocompatible population as the viability of cells was increased compared to other OMVs populations as well as the control groups in all the tested concentrations ( $5-50 \mu \mathrm{g} / \mathrm{mL}$ ). Moreover, the rate of cell viability was increased significantly, which is an indication of the increase in cell numbers (Fig. 4a). This was confirmed by WST-1 cell proliferation assay, which was found that cell proliferation was increased (Fig. 6).

Results showed that ExHp-HBS and ExHp-FBS were biocompatible in lower concentrations $(5-30 \mu \mathrm{g} / \mathrm{mL})$, while higher concentrations were found to negatively affected the cell viability. This could suggest that these two populations could contain OMVs components that have cytotoxic effects under higher concentrations. Moreover, they could be considered to be used in lower concentrations. On the other hand, a significant cytotoxic effect on cell viability was observed when macrophage RAW 264.7 was treated with ExHp-Chlos in all used concentrations except the lowest concentration $5 \mu \mathrm{g} / \mathrm{mL}$. This is an indication of the high cytotoxic effect of ExHp-Chlos that affected cell viability. This could be attributed to the composition of ExHp-Chlos that might contain cytotoxic components, which affected the cell viability even in lower concentrations.

SDS-PAGE revealed that protein contents differed in all obtained four populations (Fig. 3b). This suggests that the difference in OMVs components is responsible for the difference in the cytotoxic effect of isolated OMVs populations on macrophage RAW 264.7 cells. Thus, ExHpHBS, ExHp-FBS, and ExHp-Chlos might compose biomolecules and virulence factors that can compromise various physiological functions, leading to negatively impacting the cells. Several H. pylori's components were found to affect the host cells, such as macrophages and epithelial cells. These components include urease, VacA, lipopolysaccharide (LPS), CagA, and $\gamma$-glutamyl transpeptidase. ${ }^{[31-36]}$ Thus, depending on the OMVs population composition, different effect on the cell is expected.

OMVs released from A. nosocomialis were found to reduce the viability of HEp-2 cells in concentrations higher than 20 $\mu \mathrm{g} / \mathrm{mL}$, which suggested the reduction of cell viability was caused by OMVs delivering cytotoxic factors. ${ }^{[49]}$ Bacterial toxins such as cytolethal distending toxin (CDT), vacuolating cytotoxin A (VacA), ClyA cytotoxin, necrotizing factor type 1 (CNF1), and $\alpha$-hemolysin, which are associated with several pathogenic Gram-negative bacteria are secreted by OMVs and were reported to negatively affect cell viability. ${ }^{[50-54]}$ Moreover, multiple virulence factors could be delivered into the host cells all at the same time through OMVs to cause a simultaneous reduction in cell viability. For example, virulence factors, such as alkaline phosphatase, $\beta$-lactamase, hemolytic phospholipase $\mathrm{C}$, as well as Cif were found to be delivered directly inside the host cytoplasm by OMVs, and then they were distributed rapidly to different subcellular sites leading to affect cell viability. ${ }^{[5]}$

Red blood cells could be negatively influenced by pathogenic bacteria and their related toxins. Various bacterial toxins and virulence factors can damage RBCs which cause intravascular hemolysis or could result in accelerating the damage of RBCs by the spleen and liver. ${ }^{[56,57]}$ For instance, Clostridium perfringens $\alpha$-toxin induces hemolysis in the 
RBCs as a result of its lipolytic enzymatic activities (sphingomyelinase and phospholipase C). This leads to hydrolyze unsaturated phosphatidylcholine and sphingomyelin to toxic compounds, which damage the membranes of the RBCs causing intravascular hemolysis. ${ }^{[56]}$ In addition, bacterial toxins can change the morphology and physical properties of the RBCs membranes resulting in impairing erythropoiesis and inhibiting erythroid differentiation as well as RBCs production. ${ }^{[58]}$ The membrane of the RBCs is a target for a variety of pore-forming cytolysins

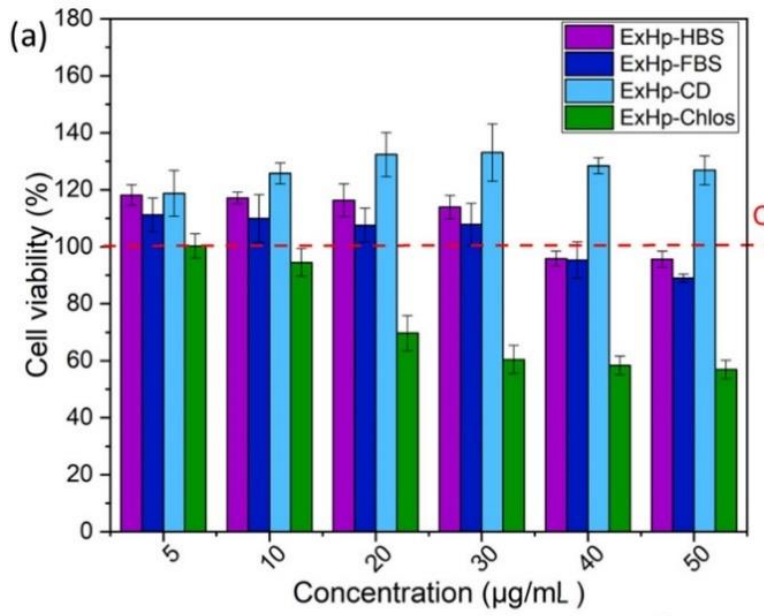

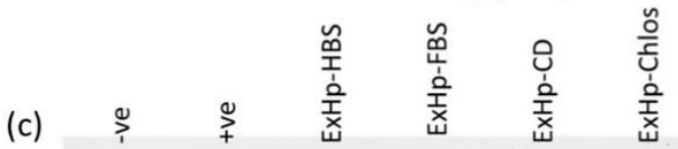

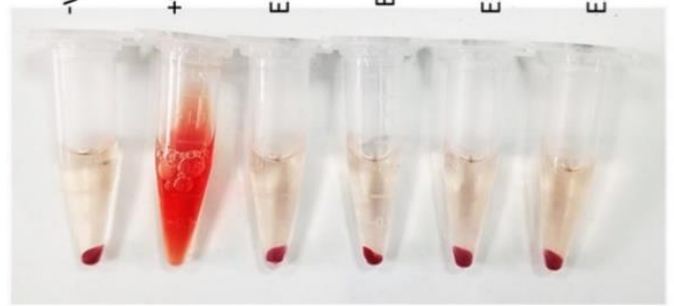

(d)
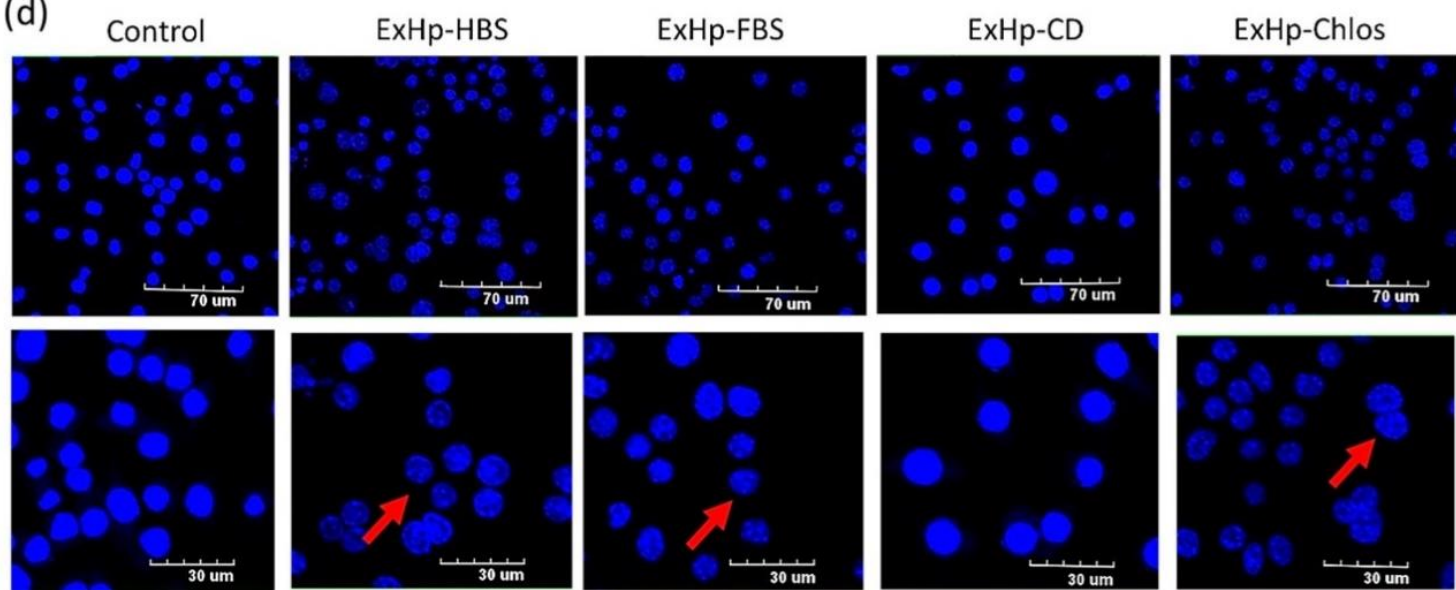

Fig. 4 The effect of different population of OMVs on macrophage RAW 264.7 cell viability in vitro (a). Seeded cells (24 h) were cultured with OMVs (5 - $50 \mu \mathrm{g} / \mathrm{mL}$ ) for $24 \mathrm{~h}$. (b) Hemolysis (\%) assay of red blood cells (RBCs) treated with different populations of OMVs incubated for $4 \mathrm{~h}$. Photo image of Eppendorf tubes showing the results of Hemolysis assay and confirmed by measuring the absorbance at $550 \mathrm{~nm}$ (c). (d) Nuclear change of macrophage RAW 264.7 cells treated with $40 \mu \mathrm{g} / \mathrm{mL}$ of OMVs populations for $24 \mathrm{~h}$ in comparison to control group cells. Chromatin condensation and nuclear fragmentation are indicated by the red arrows. $(* * *)$ $P<0.001$; (NS) Not significantly different $(\mathrm{n}=5)$. 
In conclusion, OMVs contents should be highly considered as they could contain multiple virulence factors and biomolecules that simultaneously affect the viability of the host cells. Our data revealed that the same bacterial strain $(H$. pylori) that was stimulated with different growth supplements produced different OMVs populations. These different OMVs populations contained different compositions, which lead to different biological effects on the host cell (Fig. 3b \& Figs. 4a $\&$ c). Moreover, the OMVs concentration used for stimulating the host cells should be determined in accordance with the amount of OMVs that could be applicable in the needed application but still can guarantee a low cytotoxicity rate. In this way, the full potential of OMVs could be achieved.

\subsection{Effect of OMVs populations on the change in nuclear morphology}

Fluorescence microscopy photos revealed the nuclear morphology changes, which were verified using DAPI staining on RAW 264.7 cells stimulated with $40 \mu \mathrm{g} / \mathrm{mL}$ of ExHp-HBS, ExHp-FBS, ExHp-CD, and ExHp-Chlos. Fig. 4c shows chromatin condensation and nuclear fragmentation in RAW 264.7 cells treated with $40 \mu \mathrm{g} / \mathrm{mL}$ of ExHp-HBS, ExHpFBS, and ExHp-Chlos, which is a hallmark for apoptosis. On the other hand, nuclear morphology for RAW 264.7 cells with $40 \mu \mathrm{g} / \mathrm{mL}$ treated of ExHp-CD displayed the same nuclear
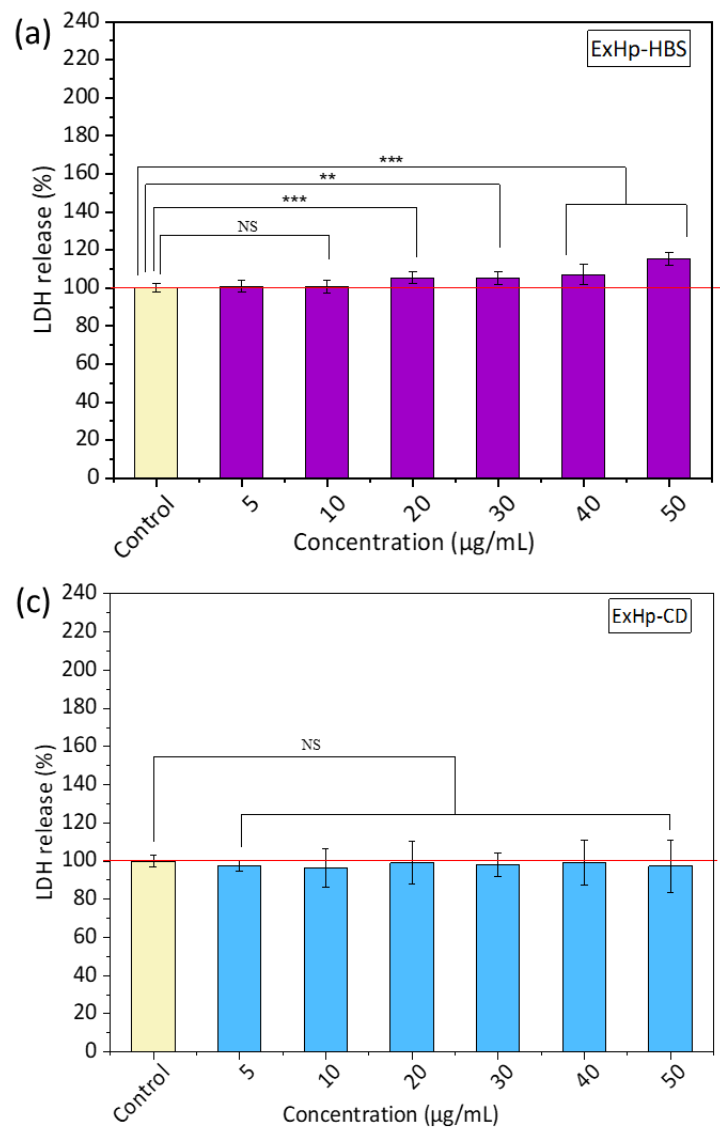

morphology for those in untreated RAW 264.7 cells (control groups), which showed no sign of chromatin condensation and nuclear fragmentation. This demonstrates that ExHp-HBS, ExHp-FBS, and ExHp-Chlos induced apoptosis which is hallmarked by chromatin condensation and nuclear fragmentation. Meanwhile, ExHp-CD maintained to keep the cell nuclei unaffected, thus a sign of the biocompatibility of ExHp-CD under the used concentration. Comparatively, all these results suggesting better biocompatibility of ExHp-CD compared to all other OMVs populations. Despite all the potential that OMVs could offer, some OMVs that contain virulence factors could affect the host cells negatively by causing apoptosis. ${ }^{[62,63]}$ For instance, OMVs from E. coli O104:H4 strain reported carrying virulence factors that caused apoptosis in the epithelial cells in the human intestine. ${ }^{[63]}$ These virulence factors could directly target the nucleus of the host cells resulting in inducing cytotoxicity and causing apoptosis. ${ }^{[64]}$ Similarly, $N$. gonorrhoeae produced OMVs that target PorB into the mitochondria leading to inducing apoptosis. ${ }^{[65]}$ These findings clearly show that OMVs contained virulence factors have the potential to cause cell apoptosis in the host cells and change the nuclear morphology, while OMVs that lack those virulence factors could exhibit a better biocompatible effect. In the current work, four OMVs populations were isolated. Among these OMVs populations,
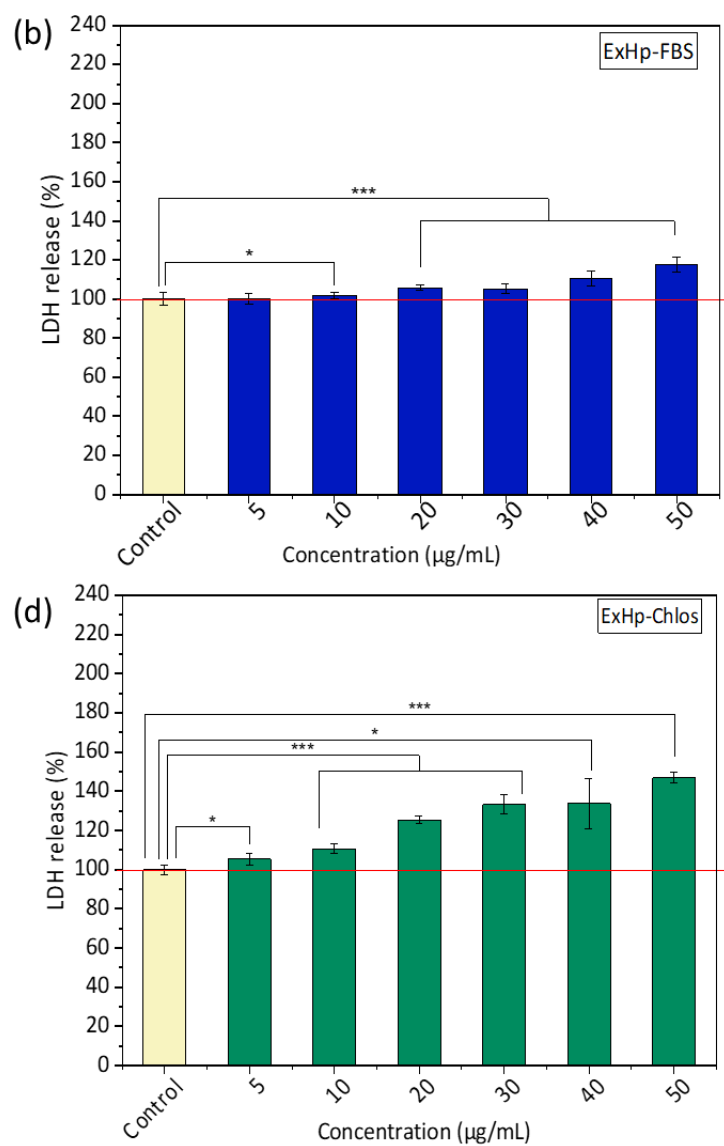

Fig. 5 LDH release assay for macrophage RAW 264.7 cells treated with 5 to $50 \mu \mathrm{g} / \mathrm{mL}$ of (a) ExHp-HBS, (b) ExHp-FBS, (c) ExHp-CD and (d) ExHp-Chlos for $48 \mathrm{~h}$ compared to untreated cells. (***) $P<0.001 ;(* *) P<0.01 ;(*) P<0.05$; (NS) Not significantly different. 
three (ExHp-HBS, ExHp-FBS, and ExHp-Chlos) exhibited nuclear morphology in macrophage RAW 264.7 cells which could be attributed to their contents, while ExHp-CD didn't cause any chromatin condensation and nuclear fragmentation (Fig 3b \& Fig. 4c).

\subsection{Lactate dehydrogenase release assay}

Lactate dehydrogenase (LDH) assay was performed to test the cytotoxic effect of ExHp-HBS, ExHp-FBS, ExHp-CD and ExHp-Chlos (5 to $50 \mu \mathrm{g} / \mathrm{mL}$ ) on RAW264.7 cells from culture supernatants after incubation for $48 \mathrm{~h}$. As shown in Fig. 5, increased levels of LDH were observed for RAW264.7 cells stimulated with ExHp-Chlos from $5 \mu \mathrm{g} / \mathrm{mL}$ to $50 \mu \mathrm{g} / \mathrm{mL}$ concentrations, which the increase in LDH levels were steadily increased with the increase of OMVs concentration. Meanwhile, for macrophages RAW264.7 cells stimulated with ExHp-CD results were in line with those of control groups indicating no cytotoxic effect that leads to an increase in LDH levels. On the other hand, LDH release from macrophages RAW264.7 cells stimulated with ExHp-HBS and ExHp-FBS were found to increase in the highest concentrations as it was $110.6 \pm 3.8 \%$ for $40 \mu \mathrm{g} / \mathrm{mL}$ and $117.8 \pm 3.7 \%$ for $50 \mu \mathrm{g} / \mathrm{mL}$; meanwhile, it was $107.1 \pm 5.5 \%$ for $40 \mu \mathrm{g} / \mathrm{mL}$, and $115.5 \pm$ $3.36 \%$ for $50 \mu \mathrm{g} / \mathrm{mL}$ for macrophages RAW264.7 cells stimulated with ExHp-HBS.

Lactate dehydrogenase (LDH), which is a normal living cell endoenzyme, and its release in cell culture supernatant reflects the compromised cell membrane integrity. Results showed that there was no significant change in LDH levels in all groups treated with ExHp-CD ( 5 to $50 \mu \mathrm{g} / \mathrm{mL}$ ) and the control groups Fig. 5c. This is evidence that ExHp-CD in all used concentrations has no cytotoxic effect that leads to disturbing the cell integrity and release of intracellular contents. This was not observed with other OMVs populations, in which LDH levels were increased either only in higher concentrations (40 and $50 \mu \mathrm{g} / \mathrm{mL}$ for ExHp-HBS and ExHpFBS) or in almost all the used concentrations (ExHp-Chlos), suggesting destruction in cell membrane integrity and release of the intracellular contents. These results are in line with the results from the cell viability test using CCK-8 (Fig. 4a). Previous studies reported that OMVs could induce cytotoxicity in the host cells, and that was attributed to the presence of cytotoxic components in the OMVs. ${ }^{[49,66,67]}$ These cytotoxic components could affect cell membrane integrity leading to the release of the intracellular contents. For instance, OMVs from E. coli contained necrotizing factor type 1 (CNF1) that is a well-known toxin that could decrease the fluidity of the polymorphonuclear leukocytes membrane (PMNs). ${ }^{[52]}$ Various virulence-associated proteins were found in OMVs released from Acinetobacter nosocomialis that exhibited cytotoxic effects against HEp-2 cells. ${ }^{[49]}$ Similarly, the cytotoxicity of OMVs secreted from Acinetobacter baumannii against macrophages was linked to the cytotoxic impact of the outer membrane protein $\mathrm{A}$ that was packaged inside the obtained OMVs. ${ }^{[67]}$ With regards to our current results, the cytotoxic effect of the highest concentrations of ExHp-HBS and ExHp-FBS (40 and $50 \mu \mathrm{g} / \mathrm{mL}$ ) compared to the lower concentrations ( 5 to $30 \mu \mathrm{g} / \mathrm{mL}$ ) were in agreement with a previous study that found OMVs from A. baumannii did not show any cytotoxic effect on the concentrations $\leq 15 \mu \mathrm{g} / \mathrm{mL}$, while concentrations $\geq 20 \mu \mathrm{g} / \mathrm{mL}$ induced cytotoxic effect, moreover, cellular shrinkage, cell detachment and rounding of cells were observed. ${ }^{[66]}$ This was speculated by the ability of OMVs to deliver bacterial effectors and cytotoxic biomolecules into the host cells, which lead to an increase in their cytotoxic effects with the increase of the concentrations of OMVs and their cytotoxic cargo. However, this cytotoxic effect was intense in the case of macrophages treated with ExHp-Chlos, which suggests a more cytotoxic effect of the OMVs and their cargo. Thus, this leads to conclude that ExHp$\mathrm{CD}$ its cargo is the most biocompatible OMVs among all obtained OMVs populations in the current study.
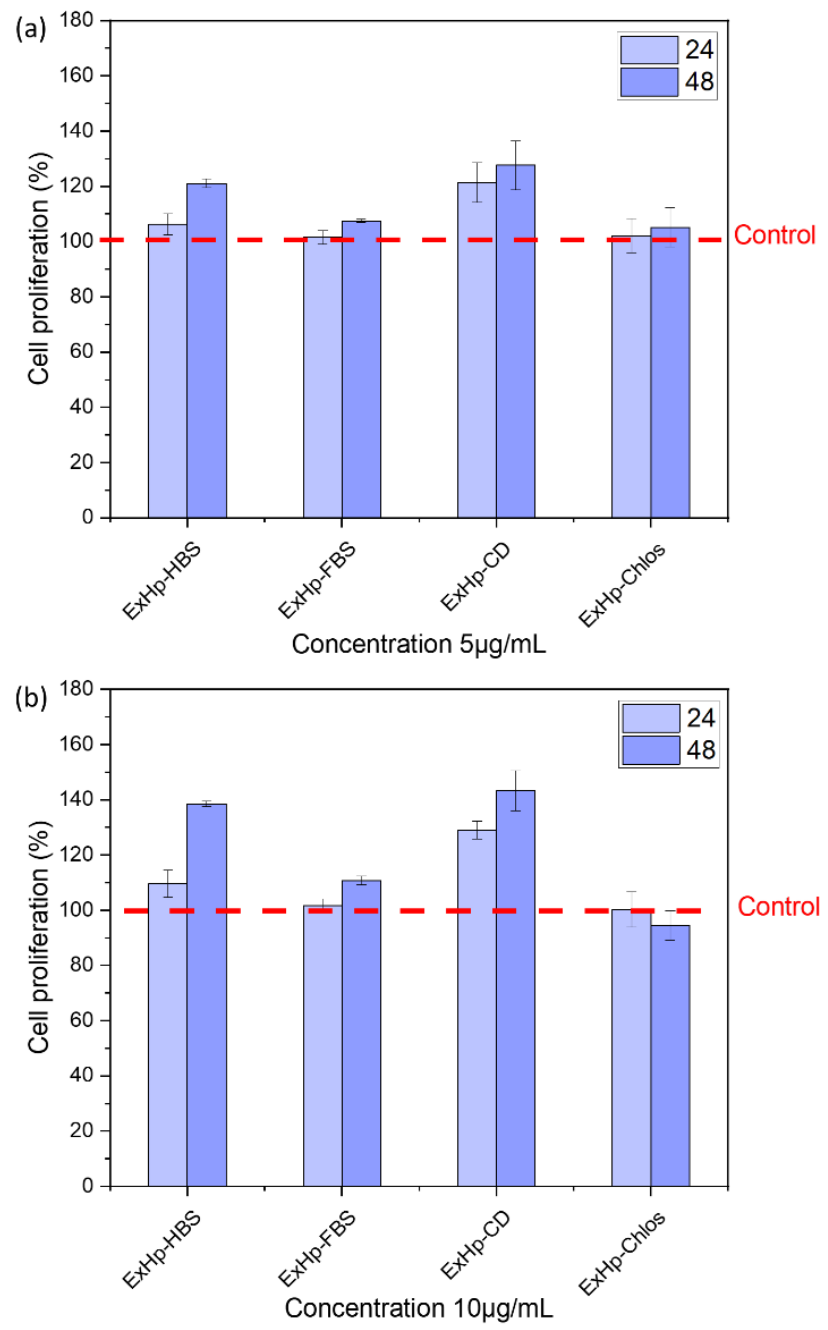

Fig. 6 WST-1 Cell Proliferation Assay for macrophage RAW 264.7 cells treated with 5 (a) and 10 (b) $\mu \mathrm{g} / \mathrm{mL}$ of OMVs populations for 24 and $48 \mathrm{~h}$. The WST-1 assay utilizes a cellular metabolism marker for cellular metabolic activity, which is an indication of an increase in cell proliferation. WST-1 assay was compared amongst treated and control groups. Values are means $\pm \operatorname{SD}(n=5)$. 


\subsection{The effect of OMVs populations on macrophage RAW} 264.7 proliferation

The effect of ExHp-HBS, ExHp-FBS, ExHp-CD, and ExHpChlos (5 and $10 \mu \mathrm{g} / \mathrm{mL}$ ) on the proliferation of RAW 264.7 cells was determined using WST-1 assay after 24 and $48 \mathrm{~h}$ incubation. Results showed that ExHp-HBS and ExHp-CD increased cell proliferation rate significantly compared to the control groups (Fig. 6). These results are an indication of the increase in cellular metabolic activity due to the increase in cell numbers. On the other hand, the cell proliferation rate was moderately increased when stimulating macrophage RAW 264.7 with ExHp-FBS compared to ExHp-HBS and ExHp$\mathrm{CD}$. On the contrary, cell proliferation was negatively affected and decreased when stimulating macrophage RAW 264.7 with $10 \mu \mathrm{g} / \mathrm{mL}$ of ExHp-Chlos after $48 \mathrm{~h}$ (Fig. 6). These results are in agreement with OMVs obtained from A. baumannii that affected cell proliferation negatively in concentrations higher than $20 \mu \mathrm{g} / \mathrm{mL}$, which was evaluated by using WST-1 assay. ${ }^{[66]}$ H. pylori have been associated with over-expression of the cycle-regulators of the host cells, which resulted in elevated levels of cell proliferation. ${ }^{[68]}$ However, the various $H$. pylori's components were found to differently affect cell proliferation. When the host cell stimulated with different $H$. pylori's components some components could affect cell proliferation negatively while others could induce hyper cell proliferation. For example, LPS were found to affect cell proliferation negatively that leads to inhibit cell proliferation, meanwhile surface antigens (GE), CagA and UreA exhibited the ability to induce high levels of cell proliferation. ${ }^{[37,38]}$ Moreover, VacA has a direct impact against $\mathrm{T}$ cells that inhibit its proliferation. This also was observed against other cell types like epithelial cells and phagocytes. ${ }^{[39-43]}$ Our findings are constant with these reports as the different contents of ExHpHBS, ExHp-FBS, ExHp-CD and ExHp-Chlos (Fig. 6) leads to different impact on cell proliferation. Thus, ExHp-CD that induced high levels of cell proliferation and better impact on macrophage RAW 264.7 deserves to be further investigated.

\subsection{Uptake of OMVs populations by RAW 264.7 cells}

The uptake of foreign antigens by macrophage cells leads to activate the macrophages and induce the immune response. Because OMVs contain several bacterial-derived antigens, so they have the ability to be taken up by macrophage cells and therefore induce immune response. ${ }^{[69,70]}$ Thus, to determine whether obtained OMVs populations can be taken up by macrophage RAW 264.7 cells, ExHp-HBS, ExHp-FBS, ExHp-CD, and ExHp-Chlos were prelabeled using DiO and then were incubated with RAW 264.7 cells for $24 \mathrm{~h}$. After fixation and cell nuclei staining, cells were viewed using a confocal laser scanning microscope. In Fig. 7, the green fluorescence that was viewed in cytoplasms' represents the prelabeled-DiO-OMVs populations, which is an indication of the huge number of ExHp-HBS, ExHp-FBS, ExHp-CD, and ExHp-Chlos that were taken up by RAW 264.7 cells.

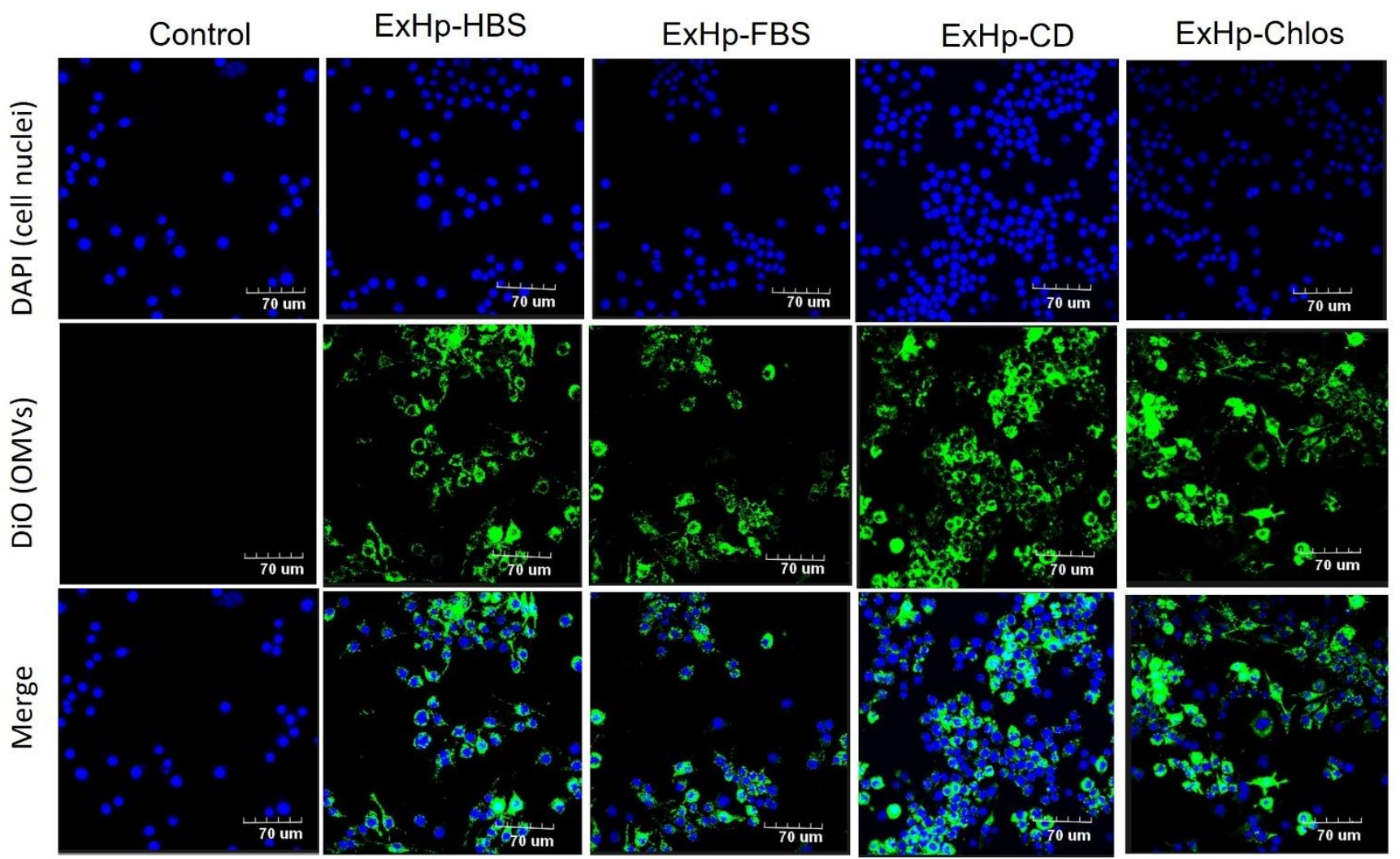

Fig. 7 The uptake of OMVs populations by macrophage RAW 264.7 cells. DiO-labeled OMVs $(10 \mu \mathrm{g} / \mathrm{mL})$ was added to the macrophage RAW 264.7 cells. Untreated cells were used as controls. Fluorescence microscopy photos showing green for OMVs (DiO) and blue for cell nuclei (DAPI). 

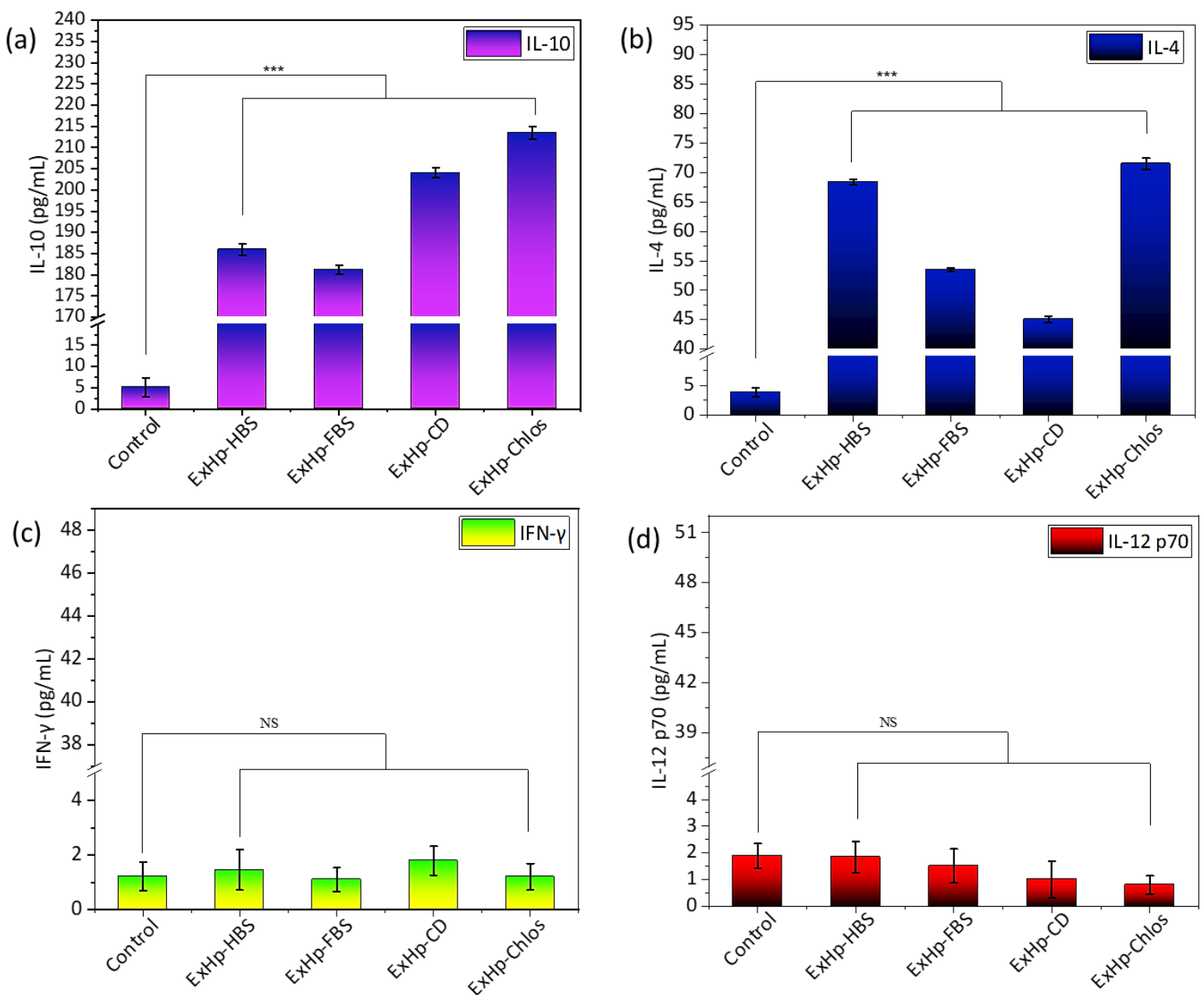

Fig. 8 Macrophage RAW 264.7 cytokines production by stimulation with OMVs $(10 \mu \mathrm{g} / \mathrm{mL})$ compared to control. RAW 264.7 cells supernatants were analyzed by specific colorimetric sandwich ELISA for (a) IL-10, (b) IL-4, (c) IFN- $\gamma$, and (d) IL-12 p70 after 24 h stimulation. The mean \pm SD of five experiments is shown. (***) $P<0.001$; (NS) Not significantly different.

Bacterial OMVs act as external foreign bodies to the host cells. This is attributed to their nature that composed of various components from their parental cell. Macrophages are classical immune cell types that induce potent immune responses once stimulated with OMVs. OMVs were found to be phagocyted by macrophages leading to activate macrophages and produce cytokines. ${ }^{[69,71]}$ Moreover, OMVs phagocyted by macrophages were found to elect several immune responses. ${ }^{[72-74]}$ Our current work revealed that ExHpHBS, ExHp-FBS, ExHp-CD, and ExHp-Chlos were phagocyted by macrophage RAW 264.7 cells (Fig. 7). Thus, they have the potential to induce an immune response.

\subsection{Effect of OMVs populations on cytokines production} Cytokines production variations during ExHp-HBS, ExHpFBS, ExHp-CD and ExHp-Chlos stimulation were examined using specific colorimetric sandwich ELISA to analyze IFN- $\gamma$, IL-12, IL-4, and IL-10 production levels. As shown in Figs. 8 a $\& b$, the production of IL-10 and IL-4 were significantly ( $p<0.001)$ increased after stimulation with $10 \mu \mathrm{g} / \mathrm{mL}$ of ExHpHBS, ExHp-FBS, ExHp-CD, and ExHp-Chlos compared to control. On the other hand, levels of IFN- $\gamma$ and IL-12 were not significantly increased (Figs. $8 \mathrm{c} \& \mathrm{~d}$ ).

Macrophages treated with OMVs from $P$. gingivalis were found to produce high levels of IFN $\beta$, TNF $\alpha$, IL-10, IL-12p70, and IL-6. ${ }^{[75]}$ Moreover, OMVs isolated from Legionella pneumophila (L. pneumophila) have elected a proinflammatory response in macrophages. ${ }^{[76]}$ Similar observations were found in the current work as the results showed the ability of ExHp-HBS, ExHp-FBS, ExHp-CD, and ExHp-Chlos to produce IL-4 and IL-10 that represents the election of anti-inflammatory response. These data suggested that ExHp-HBS, ExHp-FBS, ExHp-CD, and ExHp-Chlos enforced macrophages to produce anti-inflammatory cytokines. Thus, all isolated OMVs populations evoked immune response in macrophage RAW 264.7 cells.

\subsection{Differentiation of macrophage RAW 264.7 cells}

Immunofluorescence staining was done to detect CD86 (M1 cells marker), and CD206 (M2 cells marker) for macrophage RAW 264.7 cells stimulated with $10 \mu \mathrm{g} / \mathrm{mL}$ of ExHp-HBS, ExHp-FBS, ExHp-CD, and ExHp-Chlos. Compared to the control group, the groups stimulated with $10 \mu \mathrm{g} / \mathrm{mL}$ of all OMVs populations showed an increased ratio of CD206 and a 
decreased ratio of CD86 (Fig. 9). The current findings macrophage RAW 264.7 cells stimulated with ExHp-HBS, demonstrated that stimulating macrophages with ExHp-HBS, ExHp-FBS, ExHp-CD, and ExHp-Chlos exhibited ExHp-FBS, ExHp-CD, and ExHp-Chlos had resulted in the polarization of macrophages into M2-phenotype, which polarization of M2-phenotype.

During infection, macrophages begin a transitional activation state between M1 and M2 canonical states. The activation of macrophages could establish an activated proinflammatory state known as M1 type and can be characterized by CD86. Meanwhile, M2-activated macrophages establish anti-inflammatory activation state that can be characterized by CD206. ${ }^{[71]}$ The current results showed

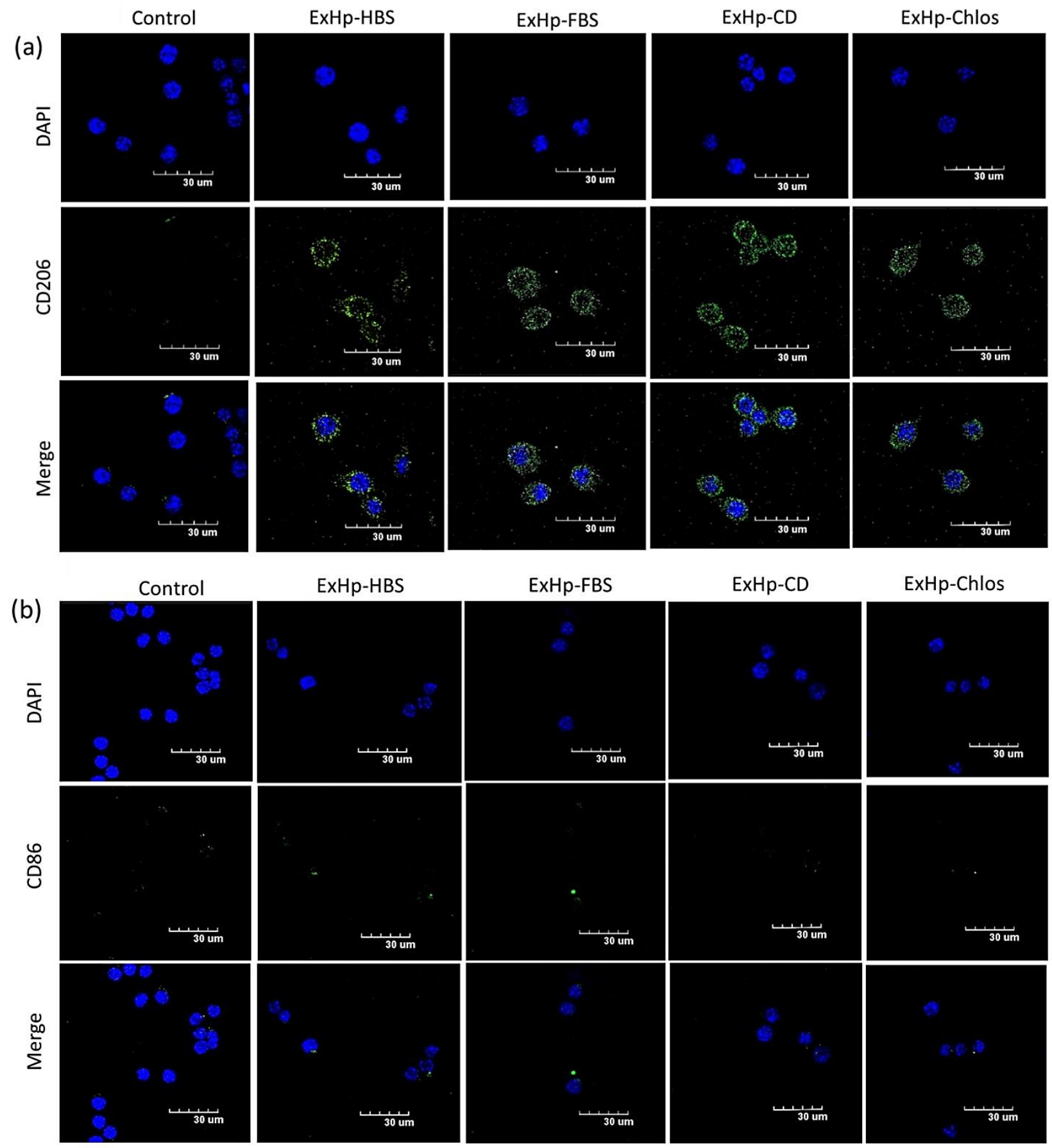

Fig. 9 Immunofluorescence staining of macrophage RAW 264.7 cells treated with $10 \mu \mathrm{g} / \mathrm{mL}$ of OMVs populations. M2 marker CD206 (a) and M1 marker CD86 (b) are showed in green and blue for cell nuclei (DAPI). Compared to the control, the groups stimulated with $10 \mu \mathrm{g} / \mathrm{mL}$ of OMVs populations showed an increased ratio of CD206 and a decreased ratio of CD86. 


\section{Conclusion}

Outer membrane vesicles originated from bacteria contain several components such as bacterial antigens, pathogenassociated molecular patterns (PAMPs), and various proteins that attracted scientists to consider OMVs in various biomedical applications. Despite all these potentials, many challenges yet need to be investigated. In the current study, four different populations of outer membrane vesicles were obtained from $H$. pylori SS1 that was cultured with HBS, FBS, $\beta$-Cyclodextrin, or Cholesterol. All the four OMVs exhibited distinct biological properties and OMVs contents. However, they all induced $\mathrm{Th} 2$ type immune response and produced antiinflammatory cytokines by macrophage RAW 264.7 in vitro. In conclusion, obtained OMVs could be influenced by many factors that should be considered when working with OMVs. Our findings revealed that growth supplements in the culture medium influenced the production of OMVs and their biological properties, which is attributed to their contents. This knowledge determines which type of OMVs population to be chosen according to the required application. This could lead to finding the required OMVs population with the desired biological function. Thus, the specific OMVs population could be used in the needed biomedical applications such as in cancer immunotherapy, anti-bacterial adhesion agents, bacterial vaccine development, and drug delivery vehicles depending on the specific biological function. This study revealed that ExHp-CD and its associated cargo are the most biocompatible OMVs among all obtained populations, which can induce an immune response. Thus, it deserves to be further investigated. Moreover, this study concludes that $\beta$ Cyclodextrin induced the production of the most biocompatible OMVs derived from $H$. pylori SS1, while Cholesterol was found to induce the production of the more cytotoxic OMVs.

\section{Conflict of interest}

There are no conflicts to declare.

\section{Acknowledgments}

This research was financially supported by the National Natural Science Foundation of China (Grant No. 21774039, 51973076) and the project of National Key Research and Development Program of China (2018YFE0123700).

\section{Supporting Information}

Not applicable.

\section{References}

[1] K. W. Kim, Applied Microscopy, 2018, 48, 96-101, doi: 10.9729/am.2018.48.4.96.

[2] S. Gill, R. Catchpole, P. Forterre, Fems Microbiol. Rev., 2019 43, 273-303, doi: 10.1093/femsre/fuy042.

[3] A. L. Leitão, F. J. Enguita, Non-coding RNAs and interkingdom Communication. Springer, 2016.

[4] L. Zavan, N. J. Bitto, E. L. Johnston, D. W. Greening, M.
Kaparakis-Liaskos, Proteomics, 2019, 19, 1-14, doi: 10.1002/pmic.201800209.

[5] L. Zavan, N. J. Bitto, M. Kaparakis-Liaskos, in Bacterial Membrane Vesicles. Springer, 2020, pp. 1-21.

[6] Z. Bolandi, N. Mokhberian, M. Eftekhary, K. Sharifi, S. Soudi, H. Ghanbarian, S. M. Hashemi, Life Sci., 2020, 259, 1-11, doi: 10.1016/j.lfs.2020.118218.

[7] Y. Li, Q. Li, D. Li, J. Gu, D. Qian, X. Qin, Y. Chen, Life Sci., 2020, 264, 1-8, doi: 10.1016/j.lfs.2020.118638.

[8] M. Yao, B. Cui, W. Zhang, W. Ma, G. Zhao, L. Xing, Life Sci, 2020, 264, 1-13, doi: 10.1016/j.lfs.2020.118658.

[9] T. Chen, G. Zhang, L. Kong, S. Xu, Y. Wang, M. Dong, Life Sci., 2019, 221, 187-195, doi: 10.1016/j.lfs.2019.02.003.

[10] J. Shao, S. Li, Y. Liu, M. Zheng, Life Sci., 2020, 240, 1-8, doi: 10.1016/j.lfs.2019.117094.

[11] E. Bagheri, K. Abnous, S. A. Farzad, S. M. Taghdisi, M. Ramezani, M. Alibolandi, Life Sci., 2020, 261, 1-10, doi: 10.1016/j.lfs.2020.118369.

[12] Y. Liu, J. Luo, X. Chen, W. Liu, T. Chen, Nano-Micro. Lett., 2019, 11, 1-46, doi: 10.1007/s40820-019-0330-9.

[13] P. Dash, A. M. Piras, M. Dash, J. Control. Release, 2020, 327, 546-570, doi: 10.1016/j.jconrel.2020.09.012.

[14] M. J. Uddin, J. Dawan, G. Jeon, T. Yu, X. He, J. Ahn, Microorganisms, $\quad 2020, \quad \mathbf{8}, \quad 1-23 \quad$ doi: 10.3390/microorganisms 8050670 .

[15] C. Schwechheimer, M. J. Kuehn, Nat. Rev. Microbiol., 2015, 13, 605-619, doi: 10.1038/nrmicro3525.

[16] S. Ayalew, A. W. Confer, B. Shrestha, A. E. Wilson, M. Montelongo, Clin. Vaccine Immunol., 2013, 20, 191-196, doi: 10.1128/cvi.00622-12.

[17] L. Turner, N. J. Bitto, D. L. Steer, C. Lo, K. D'Costa, G. Ramm, M. Shambrook, A. F. Hill, R. L. Ferrero, M. KaparakisLiaskos, Front. Immunol., 2018, 9, 1-10, doi: 10.3389/fimmu.2018.01466.

[18] A. J. Park, K. Murphy, M. D. Surette, C. Bandoro, J. R. Krieger, P. Taylor, C. M. Khursigara, J. Proteome Res., 2015, 14, 4524-4537, doi: 10.1021/acs.jproteome.5b00262.

[19] T. Pierson, D. Matrakas, Y. U. Taylor, G. Manyam, V. N. Morozov, W. Zhou, M. L. van Hoek, J. Proteome Res., 2011, 10, 954-967, doi: 10.1021/pr1009756.

[20] J. L. Kadurugamuwa, T. J. Beveridge, J. Antimicrob. Chemoth., 1997, 40, 615-621, doi: 10.1093/jac/40.5.615.

[21] K. J. McMahon, M. E. Castelli, E. G. Vescovi, M. F. Feldman, J. Bacteriol., 2012, 194, 3241-3249, doi: 10.1128/jb.00016-12.

[22] M. Li, H. Zhou, C. Yang, Y. Wu, X. Zhou, H. Liu, Y. Wang, J. Control. Release, 2020, 323, 253-268, doi: 10.1016/j.jconrel.2020.04.031.

[23] Y. Hu, Y. Zhu, N. H. Lu, Chinese Med. J., 2020, 133, 335343, doi: 10.1097/CM9.0000000000000618.

[24] O. Sjomina, J. Pavlova, Y. Niv, M. Leja, Helicobacter, 2018 , 23, 1-6, doi: 10.1111/hel.12514.

[25] J. K. Y. Hooi, W. Y. Lai, W. K. Ng, M. M. Y. Suen, F. E. Underwood, D. Tanyingoh, P. Malfertheiner, D. Y. Graham, V. W. S. Wong, J. C. Y. Wu, F. K. L. Chan, J. J. Y. Sung, G. G. 
Kaplan, S. C. Ng, Gastroenterology, 2017, 153, 420-429, doi: 10.1053/j.gastro.2017.04.022.

[26] A. Savoldi, E. Carrara, D. Y. Graham, M. Conti, E. Tacconelli, Gastroenterology, 2018, 155, 1372-1382, doi: 10.1053/j.gastro.2018.07.007.

[27] A. J. F. Egan, Mol. Microbiol., 2018, 107, 676-687, doi: 10.1111/mmi.13908.

[28] C. Xu, D. M. Soyfoo, Y. Wu, S. Xu, Eur. J. Clin. Microbiol. Infect. Dis., 2020, 39, 1821-1830, doi: 10.1007/s10096-02003948-y.

[29] M. R. Ki, I. H. Hong, J. K. Park, K. S. Hong, O. K. Hwang, J. Y. Han, A. R. Ji, S. I. Park, S. K. Lee, S. E. Yoo, K. S. Jeong, Anticancer Res., 2009, 29, 2393-2402.

[30] F. Fahimi, M. R. Tohidkia, M. Fouladi, R. Aghabeygi, N. Samadi, Y. Omidi, Bioimpacts, 2017, 7, 59-71, doi: 10.15171/bi.2017.08.

[31] M. P. Tan, J. Pedersen, Y. Zhan, A. M. Lew, M. J. Pearse, O. L. Wijburg, R. A. Strugnell, Infect Immun., 2008, 76, 1289 1297, doi: 10.1128/IAI.00779-07.

[32] M. Hatakeyama, P. Jpn Acad. B Phys., 2017, 93, 196-219, doi: 10.2183/pjab.93.013.

[33] H. H. Cheng, G. Y. Tseng, H. B. Yang, H. J. Wang, H. J. Lin, W. C. Wang, World J. Gastroentero., 2012, 18, 34-43, doi: 10.3748/wjg.v18.i1.34.

[34] W. Gonciarz, A. Krupa, K. Hinc, M. Obuchowski, A. P. Moran, A. Gajewski, M. Chmiela, PLoS One, 2019, 14, 1-27, doi: 10.1371/journal.pone.0220636.

[35] R. Kaebisch, R. Mejias-Luque, C. Prinz, M. Gerhard, J. Immunol., 2014, 192, 316-323, doi: 10.4049/jimmunol.1302476. [36] M. Denic, E. Touati, H. De Reuse, Helicobacter, 2020, 25 , 1-5, doi: 10.1111/hel.12736.

[37] E. Mnich, M. Kowalewicz-Kulbat, P. Sicinska, K. Hinc, M. Obuchowski, A. Gajewski, A. P. Moran, M. Chmiela., World J. Gastroentero., 2016, 22, 7536-7558, doi: 10.3748/wjg.v22.i33.7536.

[38] N. Ito, H. Tsujimoto, H. Ueno, Q. Xie, N. Shinomiya, J. Clin. Med., 2020, 9, 1-11, doi: 10.3390/jcm9113699.

[39] R. L. Cassady-Cain, J. C. Hope, M. P. Stevens, Infect. Immun., 2018, 86, 1-11, doi: 10.1128/IAI.00683-17.

[40] C. Utsch, R. Haas, Toxins (Basel), 2016, 8, 1-10 doi: 10.3390/toxins8060190.

[41] M. S. Sundrud, V. J. Torres, D. Unutmaz, T. L. Cover, $P$. Natl. Acad. Sci. USA, 2004, 101, 7727-7732, doi: 10.1073/pnas.0401528101.

[42] B. Gebert, W. Fischer, E. Weiss, R. Hoffmann, R. Haas, Science, 2003, 301, 1099-1102, doi: 10.1126/science.1086871.

[43] M. Boncristiano, S. R. Paccani, S. Barone, C. Ulivieri, L. Patrussi, D. Ilver, A. Amedei, M. M. D'Elios, J. L. Telford, C. T. Baldari, J. Exp. Med., 2003, 198, 1887-1897, doi: 10.1084/jem.20030621.

[44] L. B. Jones, C. R. Bell, K. E. Bibb, L. Gu, M. T. Coats, Q. L. Matthews, Biomedicines, 2018, 6, $1-12$ doi: 10.3390/biomedicines6030079.

[45] Y. Kikuchi, N. Obana, M. Toyofuku, N. Kodera, T. Soma, T. Ando, Y. Fukumori, N. Nomura, A. Taoka, Nanoscale, 2020,
12, 7950-7959, doi: 10.1039/c9nr10850e.

[46] Y. Hasegawa, H. Futamata, Y. Tashiro, Front. Microbiol., 2015, 6, 1-5, doi: 10.3389/fmicb.2015.00633.

[47] W. Zhang, X. Jiang, J. Bao, Y. Wang, H. Liu, L. Tang, Front. Immunol., 2018, 9, 1-12, doi: 10.3389/fimmu.2018.00090.

[48] M. Jarzab, G. Posselt, N. Meisner-Kober, S. Wessler, Microorganisms, $\quad 2020, \quad 8, \quad 1-19, \quad$ doi: 10.3390/microorganisms8091328.

[49] J. S. Nho, S. H. Jun, M. H. Oh, T. I. Park, C. W. Choi, S. I. Kim, C. H. Choi, J. C. Lee, Microb. Pathog., 2015, 81, 39-45, doi: 10.1016/j.micpath.2015.03.012.

[50] S. N. Wai, B. Lindmark, T. Söderblom, A. Takade, M. Westermark, J. Oscarsson, J. Jass, A. Richter-Dahlfors, Y. Mizunoe, B. E. Uhlin, Cell, 2003, 115, 25-35, doi: 10.1016/s0092-8674(03)00754-2.

[51] C. Balsalobre, J. M. Silván, S. Berglund, Y. Mizunoe, B. E. Uhlin, S. N. Wai, Mol. Microbiol., 2006, 59, 99-112, doi: 10.1111/j.1365-2958.2005.04938.x.

[52] J. M. Davis, H. M. Carvalho, S. B. Rasmussen, A. D. O'Brien, Infect. immun., 2006, 74, 4401-4408. doi: 10.1128/IAI.00637-06. [53] B. Lindmark, P. K. Rompikuntal, K. Vaitkevicius, T. Song, Y. Mizunoe, B. E. Uhlin, P. Guerry, S. N. Wai, BMC Microbiol., 2009, 9, 1-10, doi: 10.1186/1471-2180-9-220.

[54] H. Chang, D. Chen, B. Ni, Q. Zuo, C. Wang, R. Han, C. Lan, Dig. Dis. Sci., 2016, 61, 80-90, doi: 10.1007/s10620-015-3836-0. [55] J. M. Bomberger, D. P. Maceachran, B. A. Coutermarsh, S. Ye, G. A. O'Toole, B. A. Stanton, PLoS Pathog., 2009, 5, 1-13, doi: 10.1371/journal.ppat.1000382.

[56] J. McCullough, Hematology 2014, the American Society of Hematology Education Program Book, 2014, 2014, 404-409, doi: 10.1182/asheducation-2014.1.404.

[57] S. A. Jewell, R. W. Titball, J. Huyet, C. E. Naylor, A. K. Basak, P. Gologan, C. P. Winlove, P. G. Petrov, Soft. Matter., 2015, 11, 7748-7761, doi: 10.1039/c5sm00876j.

[58] T. Takagishi, M. Takehara, S. Seike, K. Miyamoto, K. Kobayashi, M. Nagahama, Sci. Rep., 2017, 7, 1-11, doi: 10.1038/s41598-017-05567-8.

[59] R. Benz, Biochim. Biophys. Acta, 2016,1858, 526-537, doi: 10.1016/j.bbamem.2015.10.025.

[60] M. C. Martino, R. A. Stabler, Z. W. Zhang, M. J. Farthing, B. W. Wren, N. Dorrell, Infect. immun., 2001, 69, 1697-1703, doi: 10.1128/IAI.69.3.1697-1703.2001.

[61] J. F. Tomb, O. White, A. R. Kerlavage, R. A. Clayton, G. G. Sutton, R. D. Fleischmann, K. A. Ketchum, H. P. Klenk, S. Gill, B. A. Dougherty, K. Nelson, J. Quackenbush, L. Zhou, E. F. Kirkness, S. Peterson, B. Loftus, D. Richardson, R. Dodson, H. G. Khalak, A. Glodek, K. McKenney, L. M. Fitzegerald, N. Lee, M. D. Adams, E. K. Hickey, D. E. Berg, J. D. Gocayne, T. R. Utterback, J. D. Peterson, J. M. Kelley, M. D. Cotton, J. M. Weidman, C. Fujii, C. Bowman, L. Watthey, E. Wallin, W. S. Hayes, M. Borodovsky, P. D. Karp, H. O. Smith, C. M. Fraser, J. C. Venter, Nature, 1997, 388, 539-547, doi: 10.1038/41483.

[62] S. Fulsundar, H. M. Kulkarni, M. V. Jagannadham, R. Nair, S. Keerthi, P. Sant, K. Pardesi, J. Bellare, B. A. Chopade, Microb. Pathog., 2015, 83-84, 12-22, doi: 10.1016/j.micpath.2015.04.005. 
[63] L. Kunsmann, C. Rüter, A. Bauwens, L. Greune, M. Glüder, B. Kemper, A. Fruth, S. N. Wai, X. He, R. Lloubes, M. A. Schmidt, U. Dobrindt, A. Mellmann, H. Karch, M. Bielaszewska, Sci. Rep., 2015, 5, 1-18, doi: 10.1038/srep13252.

[64] C. H. Choi, S. H. Hyun, J. Y. Lee, J. S. Lee, Y. S. Lee, S. A. Kim, J. P. Chae, S. M. Yoo, J. C. Lee, Cell. Microbiol., 2008, 10, 309-319, doi: 10.1111/j.1462-5822.2007.01041.x.

[65] K. Koeppen, T. H. Hampton, M. Jarek, M. Scharfe, S. A. Gerber, D. W. Mielcarz, E. G. Demers, E. L. Dolben, J. H. Hammond, D. A. Hogan, B. A. Stanton, PLOS Pathogens., 2016, 12, 1-22, doi: 10.1371/journal.ppat.1005672.

[66] S. H. Jun, J. H. Lee, B. R. Kim, S. I. Kim, T. I. Park, J. C. Lee, Y. C. Lee, PloS One, 2013, 8, 1-8, doi: 10.1371/journal.pone.0071751

[67] J. S. Jin, S. O. Kwon, D. C. Moon, M. Gurung, J. H. Lee, S. I. Kim, J. C. Lee, PloS One, 2011, 6, 1-9, doi: 10.1371/journal.pone.0017027.

[68] V. V. Subhash, B. Ho, Microbiology (Reading), 2015, 161, 1150-1160, doi: 10.1099/mic.0.000066.

[69] Y. Li, Y. Liu, F. Xiu, J. Wang, H. Cong, S. He, Y. Shi, X. Wang, X. Li, H. Zhou, Int J Nanomedicine, 2018, 13, 467-477, doi: $10.2147 /$ IJN.S151110.

[70] J. D. Cecil, N. M. O'Brien-Simpson, J. C. Lenzo, J. A. Holden, W. Singleton, A. Perez-Gonzalez, A. Mansell, E. C. Reynolds, Front. immun., 2017, 8, 1017-1017, doi: 10.3389/fimmu.2017.01017.

[71] A. L. Jung, C. Stoiber, C. E. Herkt, C. Schulz, W. Bertrams, B. Schmeck, PLoS Pathog., 2016, 12, 1-26, doi: 10.1371/journal.ppat.1005592.

[72] X. J. Gao, T. Li, B. Wei, Z. X. Yan, N. Hu, Y. J. Huang, B. L. Han, T. S. Wai, W. Yang, R. Yan, Drug. metab. dispos., 2018, 46, 292-302, doi: 10.1124/dmd.117.079046.

[73] S. Mitra, R. Sinha, J. Mitobe, H. Koley, Vaccine, 2016, 34, 1839-1846, doi: 10.1016/j.vaccine.2016.02.018.

[74] W. D. McCaig, C. L. Loving, H. R. Hughes, S. L. Brockmeier, PLoS One, 2016, 11, 1-23, doi: 10.1371/journal.pone.0149132.

[75] A. J. Fleetwood, M. K. S. Lee, W. Singleton, A. Achuthan, M. C. Lee, N. M. O'Brien-Simpson, A. D. Cook, A. J. Murphy, S. G. Dashper, E. C. Reynolds, J. A. Hamilton, Front. Cell. Infect. Microbiol., 2017, 7, 1-15, doi: 10.3389/fcimb.2017.00351.

[76] A. L. Jung, K. Hoffmann, C. E. Herkt, C. Schulz, W. Bertrams, B. Schmeck, J. Vis. Exp., 2017, doi: 10.3791/55146.

[77] R. Hu, H. Lin, J. Li, Y. Zhao, M. Wang, X. Sun, Y. Min, Y. Gao, M. Yang, BMC Microbiol., 2020, 20, 1-13, doi: 10.1186/s12866-020-01953-x.

[78] Q. Liu, X. Li, Y. Zhang, Z. Song, R. Li, H. Ruan, X. Huang, Pathog. Dis., 2019, 77, 1-13, doi: 10.1093/femspd/ftz050.

\section{Author information}

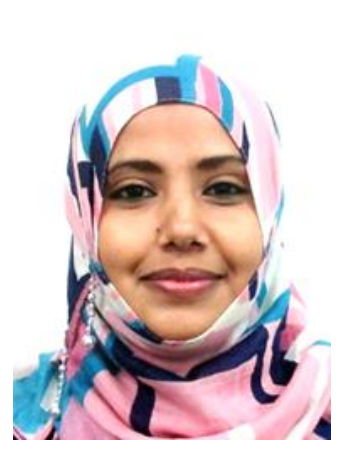

Abeer Ahmed Qaed Ahmed Affiliated at Huazhong University of Science and Technology, Wuhan, China and University of South Africa, Johannesburg, South Africa. Her research interests include microorganisms use in a variety of biomedical applications. She has published several SCI papers and book chapters.

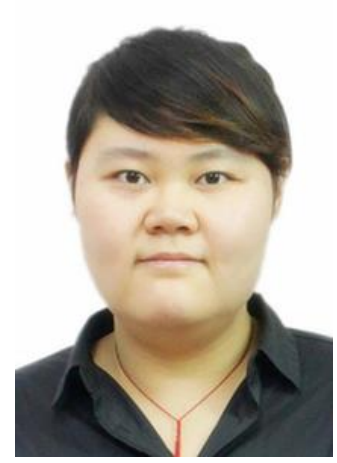

Ruizhu Zheng - Ph.D. candidate majoring in biomedical engineering. College of Life Science and Technology, Huazhong University of Science and Technology, Wuhan 430074, China. Her research focuses on biomaterials in wound healing.

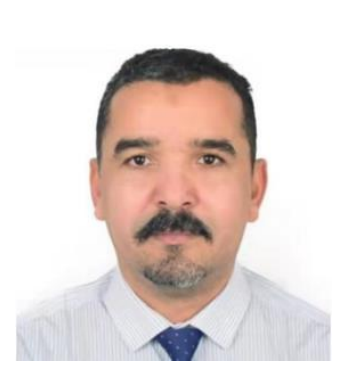

Ahmed M. E. Abdalla - Affiliated at the Department of Biochemistry, College of Applied Science, University of Bahri, Khartoum, Sudan. He was awarded a Bachelor (honors) of Biochemistry in 2002 from the Juba University, Sudan. He finished his Master's degree in 2009 from the Faculty of Medicine, Gezira University, Sudan. He obtained his Ph.D. degree from Huazhong University of Science and Technology, in Biochemistry and Molecular Biology. His research interests include cancer-associated thrombosis and tumor cell lines.

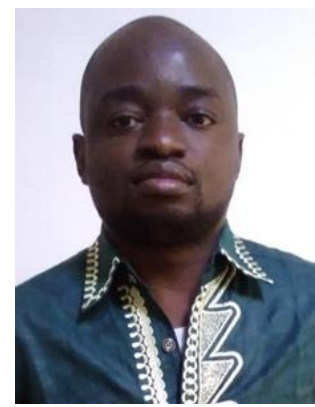

Bianza Moise Bakadia - Ph.D. candidate at Huazhong University of Science and Technology. He received the Bachelor of Science degree from the Higher Institute of Medical Technique of Lubumbashi, DR. Congo, and the master's degree from Huazhong University of Science and Technology, China. His research interests include biomedical analyzes of biological fluids, the immune response to microorganisms, and the development of biomaterials for wound healing applications. He has published 13 SCI papers. 


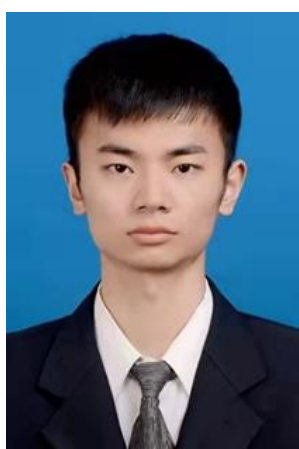

Fuyu Qi - Ph.D. candidate majoring in biomedical engineering. College of Life Science and Technology, Huazhong University of Science and Technology, Wuhan 430074, China. His research focuses on biomaterials in tissue engineering.

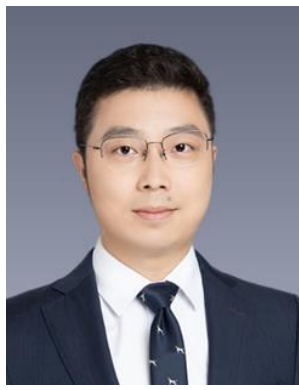

Lin Xiao - Assistant professor and graduate advisor at Sun Yat-sen University since 2020. He received his B.Sc. from Huazhong University of Science and Technology in 2009. He was a visiting Ph.D. student at McGill University and obtained his Ph.D. from Huazhong University of Science and Technology in 2015. Then, he proceeded as a postdoctoral research fellow at the Department of Biomedical Engineering at Huazhong University of Science and Technology. His research interests include biomaterials for drug delivery, especially in combination with immunotherapy against cancer.

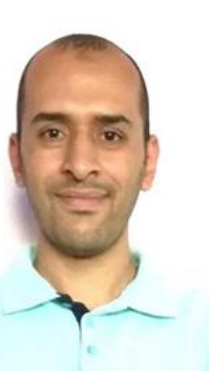

Omar Mohammad Atta- Assistant lecturer at Alazhar University's faculty of science, Assiut, Egypt. Omar is currently enrolled as a Ph.D. candidate at Huazhong University of Science and Technology, Wuhan, China. He has experience working as a quality manager in water treatment, biotechnology applications advisor, and bio-data analyst. His research interests include biomaterials, bacterial cellulose applications, and edible films for food packaging.

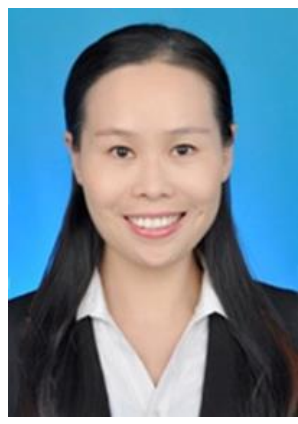

Lin Mao- She obtained her Ph.D. in Biopharmaceutical Engineering in 2021, from the College of Life Science and Technology, Huazhong University of Science and Technology, Wuhan 430074, China. Her research focuses on nanocomposite hydrogel in wound healing.

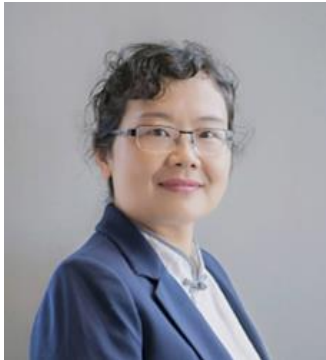

Guang Yang - Prof. Guang Yang received her $B S$ and $P h D$ degree in Polymer Science from Wuhan University in 1989 and 2000, respectively. She visited Johannes Gutenberg-Universitaet Mainz, Germany, as an Alexander von Humboldt fellow (2002-2004) and then Kyushu University in Japan as a JSPS (Japan Society for the Promotion of Science) fellow (2004-2006). In 2006, she moved to College of Life Science and Technology at Huazhong University of Science and Technology as a professor. In 2010, she was a senior visiting scholar at the University of Akron, USA. Her research interest focuses on bionic nanocomposites, nanoassembly of ordered eco-friendly materials and their structures and properties, design and fabrication of novel nanodrug transporters, and tissue engineering scaffold materials for biomedical applications, etc.

Publisher's Note: Engineered Science Publisher remains neutral with regard to jurisdictional claims in published maps and institutional affiliations. 